\title{
Glucose-derived spiro-isoxazolines are anti-hyperglycemic agents against type 2 diabetes through glycogen phosphorylase inhibition
}

David Goyard, ${ }^{\mathrm{a}}$ Bálint Kónya, ${ }^{\mathrm{b}}$ Aikaterini S. Chajistamatiou, ${ }^{\mathrm{c}}$ Evangelia D. Chrysina, ${ }^{\mathrm{c}}$ Jérémy Leroy, ${ }^{\mathrm{d}}$ Sophie Balzarin, ${ }^{\mathrm{d}}$ Michel Tournier, ${ }^{\mathrm{d}}$ Didier Tousch, ${ }^{\mathrm{d}}$ Pierre Petit, ${ }^{\mathrm{d}}$ Cédric Duret, ${ }^{\mathrm{e}, \mathrm{f}}$ Patrick Maurel, ${ }^{\mathrm{e}, \mathrm{f}}$ László Somsák, ${ }^{\mathrm{b}}$ Tibor Docsa, ${ }^{\mathrm{g}}$ Pál Gergely, ${ }^{\mathrm{g}}$ Jean-Pierre Praly, ${ }^{\mathrm{a}, *}$ Jacqueline Azay-Milhau $^{\mathrm{d}, *}$ and Sébastien Vidal $^{\mathrm{a}, *}$

${ }^{\text {a }}$ Institut de Chimie et Biochimie Moléculaires et Supramoléculaires, Laboratoire de Chimie Organique 2 Glycochimie, UMR 5246, CNRS, Université Claude Bernard Lyon 1, 43 Boulevard du 11 Novembre 1918, F69622 Villeurbanne, France. Fax: +33 472448 109; Tel: +33 472448 349; E-mail: sebastien.vidal@univlyon1.fr

${ }^{\mathrm{b}}$ Department of Organic Chemistry, University of Debrecen, POB 20, H-4010 Debrecen, Hungary.

${ }^{\mathrm{c}}$ Institute of Biology, Medicinal Chemistry \& Biotechnology, National Hellenic Research Foundation, 48 Vassileos Constantinou Avenue, Athens, GR-11635, Greece.

${ }^{d}$ Université Montpellier 1, EA7288, Centre de Pharmacologie et Innovation dans le Diabète, Montpellier, France.

${ }^{\mathrm{e}}$ INSERM, U1040, F-34295 Montpellier, France

${ }^{\mathrm{f}}$ Université Montpellier 1, UMR 1040, F-34295 Montpellier, France

${ }^{g}$ Department of Medical Chemistry, Faculty of Medicine, University of Debrecen, Egyetem tér 1, H-4032 Debrecen, Hungary.

Abstract: Glycogen phosphorylase (GP) is a target for the treatment of hyperglycaemia in the context of type 2 diabetes. This enzyme is responsible for the depolymerization of glycogen into glucose thereby affecting the levels of glucose in the blood stream. Twelve new Dglucopyranosylidene-spiro-isoxazolines have been prepared from O-peracylated exo-Dglucals by regio- and stereoselective 1,3-dipolar cycloaddition of nitrile oxides generated in situ by treatment of the corresponding oximes with bleach. This mild and direct procedure appeared to be applicable to a broad range of substrates. The corresponding O-unprotected 
spiro-isoxazolines were evaluated as glycogen phosphorylase (GP) inhibitors and exhibited $\mathrm{IC}_{50}$ values ranging from 1 to $800 \mu \mathrm{M}$. Selected inhibitors were further evaluated in vitro using rat and human hepatocytes and exhibited significant inhibitory properties in the primary cell culture. Interestingly, when tested with human hepatocytes, the tetra-O-acetylated spiroisoxazoline bearing a 2-naphthyl residue showed a much lower $\mathrm{IC}_{50}$ value $(2.5 \mu \mathrm{M})$, compared to that of the O-unprotected analog $(19.95 \mu \mathrm{M})$. The most promising compounds were investigated in Zucker fa/fa rat model in acute and sub-chronic assays and decreased hepatic glucose production, which is known to be elevated in type 2 diabetes. This indicates that glucose-based spiro-isoxazolines can be considered as anti-hyperglycemic agents in the context of type 2 diabetes.

Keywords: carbohydrates; spiro-isoxazolines; glycogen phosphorylase inhibitors; hepatocytes; Zucker rats; hepatic glucose production; type 2 diabetes.

\section{Introduction}

Type 2 diabetes (T2DM) or non-insulin-dependent diabetes mellitus (NIDDM) is characterized by two defects: relative insulin deficiency and liver and peripheral insulin resistance. T2DM, which accounts for 90 to $95 \%$ of the diabetic cases, is a multi-factorial disease of largely unknown etiology involving both genetic and environmental factors and it is closely associated to the metabolic syndrome. The worldwide prevalence of obesity and diabetes has increased substantially in recent decades, also among young adults and children. The rising incidence of these pathologies has grown to alarming levels in developing countries. It is expected that the coming decades these countries will face severe health service burdens as chronic hyperglycaemia is associated with long-term damage, dysfunction and failure of various organs such as eyes, kidneys, nerves, heart and blood vessels. To minimize such health-threatening complications, patients with T2DM must control their 
glycaemia by intensive lifestyle intervention as a primary treatment, with adequate diet and exercise, along with pharmacological therapies. ${ }^{1-2}$

Biguanides and $\alpha$-glycosidase inhibitors have therapeutic value as they limit, respectively, hepatic glucose output, and intestinal absorption of carbohydrates. Sulfonylureas and incretin mimetic drugs act by directly or indirectly increasing insulin release from the $\beta$ cells in the pancreas, while thiazolidinediones (TZD) activate peroxisome proliferatoractivated receptors (PPARs). Metformin is a biguanide now believed to be the most widely prescribed antidiabetic drug. As pharmacological treatments are inadequate for $30-40 \%$ of T2DM patients, combination therapy is frequently applied. With increasing severity of diabetes, insulin administration is prescribed and many patients progress to insulin therapy with time. In spite of substantial progress in the management of diabetic pathologies, the limitations or adverse effects of current treatments are incentive for improving diabetes management. Glycogen phosphorylase (GP) inhibition is one of the pharmacological approaches currently investigated. ${ }^{3}$

GP isozymes ${ }^{4}$ have been identified and characterized in a large number of organisms (bacteria, fungi, yeast, plants, insects, animals) and in mammalian tissues. GP is expressed mainly in the muscles, liver and brain where it permits the breakdown by phosphorolysis of glycogen to glucose-1-phosphate. GPa and GPb represent, respectively, the phosphorylated (active) and unphosphorylated (less active) isoforms. ${ }^{5}$ This enzyme has been thoroughly studied by kinetic investigations and X-ray diffraction analysis of enzyme-ligand complexes. These studies provided evidence on the binding site and binding mode of ligands to the enzyme. The accumulated information forms a rational basis for the kinetic data, but more significantly, provides a detailed view of the GP structural features with identification of several binding sites such as the active site, the inhibitor site, the allosteric and the new allosteric sites, the glycogen storage site, the phosphorylation site and an understanding of 
their roles at molecular level. ${ }^{6}$ As glycogenolysis is a key component to hepatic glucose production, generally observed excessive in T2DM, a large variety of synthetic molecules has been investigated as GP inhibitors, as a possible pharmacological control of glycaemia. The studied inhibitors mainly target the allosteric ${ }^{7}$ and new allosteric site, ${ }^{8}$ and the active site which accommodates glucose and glucose-based and related analogues, ${ }^{9-14}$ as can be seen also from general reviews. ${ }^{3,15-20}$ NMR spectroscopy has been shown recently through the fragment-based approach to offer additional techniques for probing, in solution, the binding pockets of GP, and investigating cooperativity between the various binding sites. ${ }^{21}$

Even though a large set of data has been reported from in vitro enzymatic experiments, much need to be clarified through pharmacological studies to get a better understanding of the in vivo specific response of a drug under evaluation. Its effects, which depend on pharmacokinetic and pharmacodynamic properties, are unpredictable and sometimes difficult to rationalize. For example, the inhibitory effects of indole-site effectors has been reported to be modulated by endogenous small-molecular-weight effectors of GPa activity, although at higher concentrations, indole-site GP inhibitors almost completely inhibit phosphorylase activity and retain a glucose concentration dependence. ${ }^{22-23}$ A series of benzamide derivatives, presumed to bind at the new allosteric site of GP (dimer interface) as suggested by molecular docking simulation, was found to simultaneously inhibit GP and activate glucokinase. ${ }^{24}$ GP inhibitors can not only interfere with glycogenesis, as mentioned, but also with gluconeogenesis, and the in vivo effects of AMP and indole site inhibitors have been reviewed. ${ }^{18,25-26}$ Recently, the effect of D-glucopyranosylidene-spiro-thiohydantoin (Figure 1, A) on glycogen metabolism in liver tissues of streptozotocin-induced and obese diabetic rats has been investigated. This showed the coordinated regulation of glycogen phosphorylase and synthase by $50 \mu \mathrm{M} \mathbf{A}$ in liver extracts of Wistar rats, resulting in the activation of synthase by a shortening of the latency compared to control animals. Compound $\mathbf{A}$ was also effective in 
lowering blood glucose levels and restoring hepatic glycogen content in streptozotocininduced diabetic rats. Furthermore, intravenous administration of $\mathbf{A}$ to Zucker Diabetic Fatty (ZDF) rats significantly decreased hepatic GPa levels, and the activation of synthase was initiated without any delay. $^{27}$

GP inhibition is a therapeutic approach to limit the pathogenic consequences of chronic hyperglycaemia in T2DM but also possibly tumor growth, ${ }^{28-29}$ or cerebral ischemia. ${ }^{30}$ Nevertheless, little is known about the potential of glucose-based molecules that bind at the catalytic site at cellular level, and only a few have been studied in detail in hepatocytes. ${ }^{27,31-32}$ This is why on the basis of our preliminary studies, ${ }^{33-34}$ the synthesis of additional glucosebased spiro-isoxazolines followed by kinetic investigations were performed. The more potent molecules ( $\mathrm{K}_{\mathrm{i}}$ in the low $\mu \mathrm{M}$ range) were selected for cellular assays with primary cultures of rat or human hepatocytes. The most promising molecules identified from these in vitro cellular assays were further investigated in an animal model (i.e. Zucker hyperinsulinemic rat). The glucopyranose-based analogue B of hydantocidin (Figure 1) prepared by Fleet's group was found to be a potent inhibitor of glycogen phosphorylase. ${ }^{35}$ This was an incentive for investigating chemical synthesis, kinetic measurements and crystallographic analysis of enzyme-ligand complexes. The kinetic and crystallographic data obtained showed that spirocompounds $\mathbf{A},{ }^{36} \mathbf{B},{ }^{35} \mathbf{C},{ }^{35}$ and $\mathbf{D}^{37}$ are competitive inhibitors and are bound at the enzyme catalytic site through a network of stabilizing interactions. By exploiting stereoselective 1,3dipolar cycloadditions, we have also synthesized glucopyranose-based spiro-isoxazolines ${ }^{33-34}$ (e.g. E) and spiro-oxathiazoles ${ }^{38-40}$ (e.g. F) which were found among the best inhibitors of GP targeting the catalytic site. ${ }^{39}$ Glucopyranosylidene-spiro-iminothiazolidinone derivatives G were reported recently as good GP inhibitors, ${ }^{41}$ while spiro-oxazolidinones $\mathbf{H}$ proved practically inactive against the enzyme. ${ }^{42}$

The present report discloses further synthetic and kinetic, as well as in vitro and in 
vivo pharmacological evaluation of new representatives of type $\mathbf{E}$ compounds to determine the properties of such glucose-based GP inhibitors as potential anti-hyperglycemic agents in the context of type 2 diabetes.

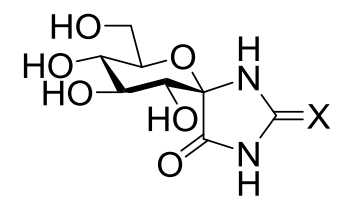

$$
\begin{aligned}
& \text { AX }=S K_{i}=5.1 \mu \mathrm{M} \\
& \text { BX }=O K_{i}=3.1 \mu \mathrm{M}
\end{aligned}
$$



C

$K_{\mathrm{i}}=320 \mu \mathrm{M}$

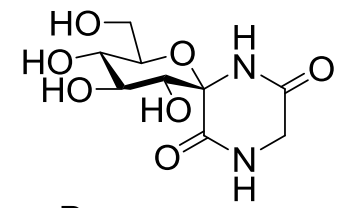

D

$K_{\mathrm{i}}=59.7 \mu \mathrm{M}$
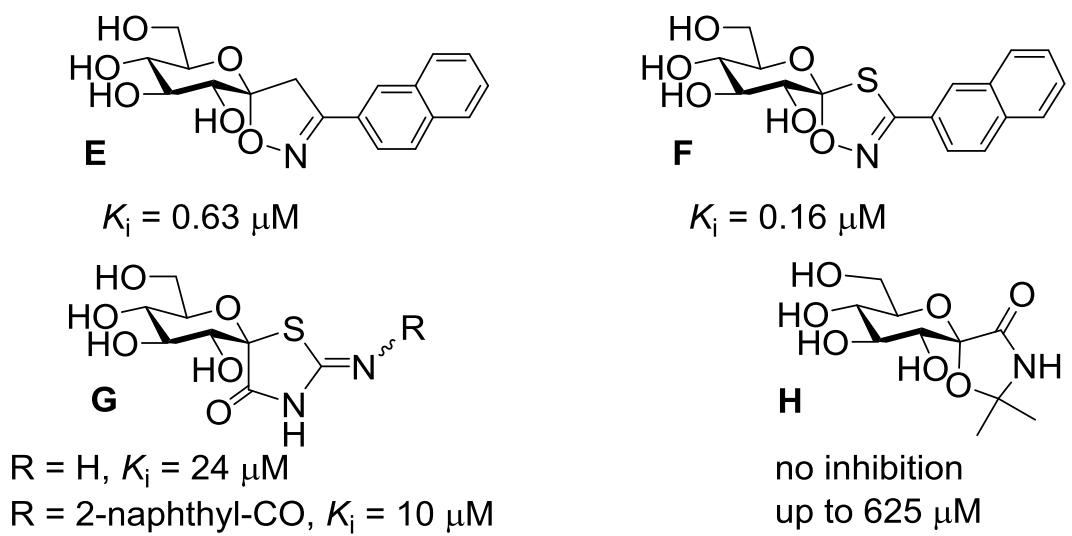

$\mathbf{F}$

$K_{\mathrm{i}}=0.16 \mu \mathrm{M}$

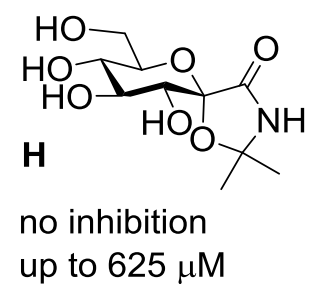

Figure 1: Various types of spiro-anomeric carbohydrate derivatives: structures, bioactivities, or inhibitory properties against rabbit muscle glycogen phosphorylase b (RMGPb)

\section{Results and Discussion}

Synthesis of GP inhibitors

Based on our previous results showing that the 2-naphthyl substituted spiro-isoxazoline $\mathbf{E}$ (Figure 1) was a potent inhibitor of GP, ${ }^{33-34}$ a new series of spiro-isoxazolines was obtained by cycloaddition of nitrile oxide intermediates to the peracetylated exo-glucal $\mathbf{3} \mathbf{A}^{34,43-44}$ and perbenzoylated exo-glucal $\mathbf{3 B}^{43-44}$ (Scheme 1). As precursors of nitrile oxides, the required oximes 1a-i,l-s were prepared in high yield upon heating commercially available aldehydes with hydroxylamine hydrochloride under basic conditions (Method A). The 6(triisopropylsilyloxy)-2-naphthaldehyde oxime $\mathbf{1} \mathbf{j}$ was prepared in a three step sequence from 
6-bromonaphthalen-2-ol that was subjected successively to O-silylation, low temperature treatment with $\mathrm{n}$-BuLi to achieve bromine-lithium exchange then formylation with $\mathrm{DMF},{ }^{45}$ and conversion to oxime $\mathbf{1 j}$.

Initially, and according to our previous results, ${ }^{33-34}$ oximes $\mathbf{1 b - e , h}$ were reacted with $N$ chlorosuccinimide (NCS) to afford the corresponding aryl $\alpha$-chloroaldoximes $\mathbf{2 b - e , h}$ (Method B). They underwent hydrochloric acid elimination in the presence of $\mathrm{NEt}_{3}$ to produce reactive nitrile oxides capable of 1,3-dipolar cycloaddition to 3A-B (Method C). This procedure led to the desired spiro-isoxazolines $\mathbf{4 b - e , h}$ in high yields (Table 1). Generation of nitrile oxides from oximes was also attempted using chloramine- $\mathrm{T}^{46}$ (to yield the $\alpha$-chloroaldoxime intermediate) or hypervalent iodine ${ }^{47}$ (to afford the nitrile oxide in situ) but none of these conditions was satisfactory. We adapted and applied simpler conditions, with slow addition of a sodium hypochlorite solution ${ }^{48}$ to THF solutions of $\mathbf{3 A - B}$ and a selected oxime, for in situ generation of nitrile oxides (Method D). ${ }^{49-50}$ This one-pot procedure was advantageous both in terms of simplicity and efficiency, as seen when comparing the yields recorded for the synthesis of $\mathbf{4 h}$ by Methods C and D (Table 1). While two or more equivalents of the oximes $\mathbf{1 a}, \mathbf{f}-\mathbf{j}, \mathbf{l}-\mathbf{n}$ were used (Method C), the cycloaddition was performed with only 1.1 equivalent of oximes 10-s (Method D). These conditions were found efficient in all cases tested, as formation of nitrile oxide-derived byproducts was limited therefore simplifying purifications. ${ }^{51}$ Moreover, chlorination of electron-rich aromatic systems (e.g. 3,5-dimethoxyphenyl, 6-methoxy-naphthalen-2-yl, benzofuran, quinoline derivatives) could be avoided using Method D, while this side-reaction occurred for the aryl $\alpha$-chloroaldoximes synthesis with NCS (Method B). For all spiro-products, only one diastereoisomer was observed, the dipole approaching the exo-glucal dipolarophile from the $\alpha$-side in the cycloaddition transition state. ${ }^{52-53}$ The spiro-isoxazoline $4 \mathbf{k}$ with a 6-hydroxy-2-naphthyl substituent was prepared from the precursor $\mathbf{4 j}$ upon desilylation with TBAF. Zemplén deacetylation of the 
spiro-isoxazolines $\mathbf{4 b}$-i,k-s led to the corresponding O-unprotected products $\mathbf{5}$ in high yield, but under these conditions $4 \mathbf{a}$ was transformed into a ring-opened isoxazole 5a' (see supporting information) which could not lead to the desired spiro-isoxazoline framework. This may be due to the electron withdrawing properties of the p-trifluoromethylphenyl residue, which made the methylene protons of the isoxazoline ring more acidic and susceptible to basic attack, so that aromatization took place, resulting in opening of the glucose ring. In previous related studies, similar 1,2-eliminations ${ }^{34,54}$ or aromatization with ring opening ${ }^{39}$ were observed.
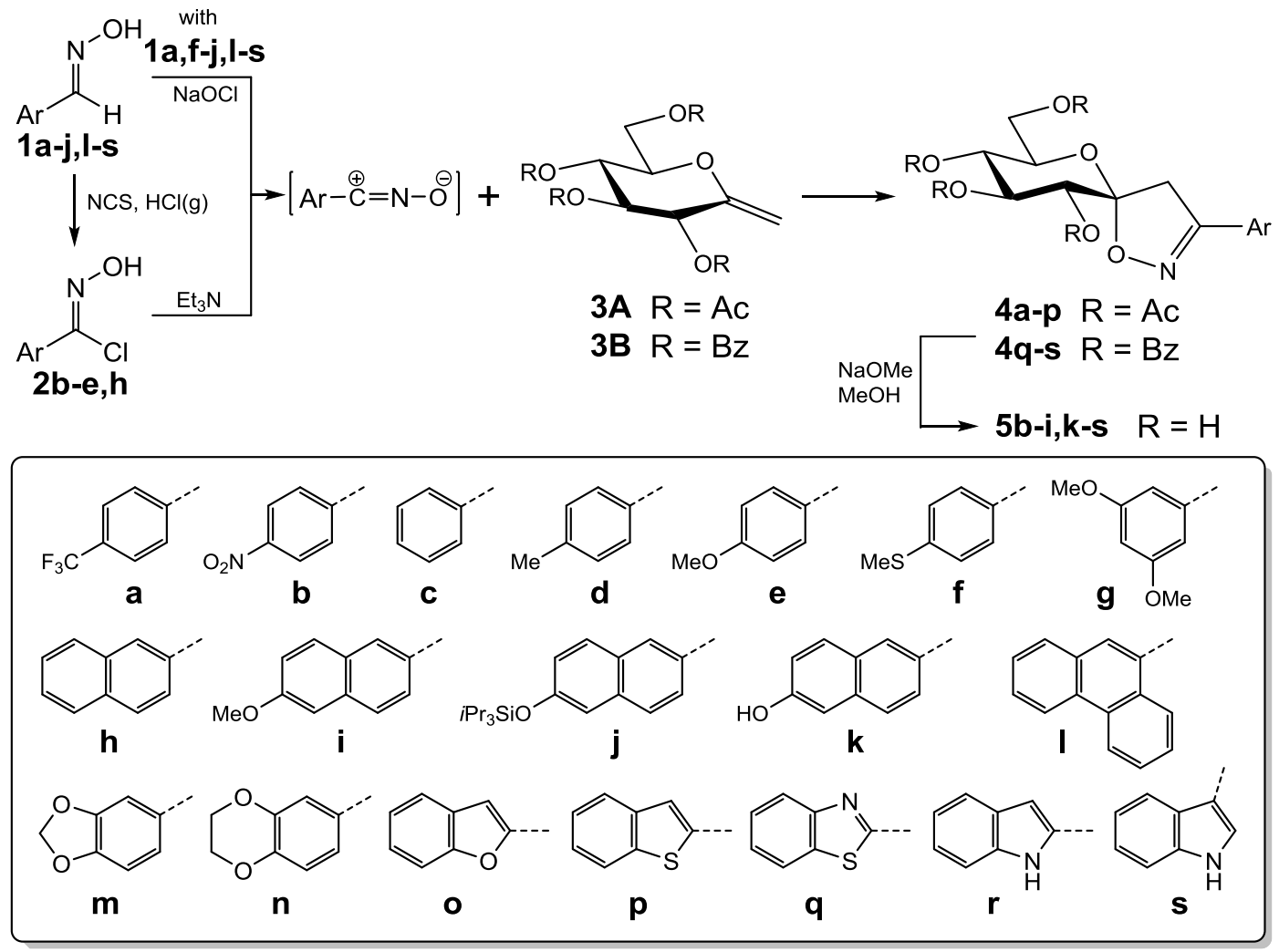

Scheme 1: Synthesis of spiro-isoxazolines by nitrile oxides cycloaddition to exo-glucals ${ }^{33,38}$ 
Table 1: Synthesis of $O$-peracylated and $O$-unprotected D-glucopyranosylidene-spiroisoxazolines $\mathbf{4}$ and $\mathbf{5}$

\begin{tabular}{|c|c|c|c|c|}
\hline $\mathrm{Ar}=$ & Compounds & $\begin{array}{l}\text { Cycloaddition Yield } \\
\%{\text { (conditions })^{\mathrm{a}}}\end{array}$ & Compounds & $\begin{array}{l}\text { Deacylation } \\
\text { Yield }(\%)^{\mathrm{b}} \\
\end{array}$ \\
\hline $\mathrm{Ph}-p-\mathrm{CF}_{3}$ & $4 a$ & 93 (D) & $5 \mathbf{5 a}$ & n.a. ${ }^{\mathrm{c}}$ \\
\hline $\mathrm{Ph}-p-\mathrm{NO}_{2}$ & $4 \mathbf{b}$ & $94(\mathrm{C})$ & $\mathbf{5 b}$ & $99^{\mathrm{d}}$ \\
\hline $\mathrm{Ph}$ & $4 c$ & $99(\mathrm{C})$ & $5 \mathrm{c}$ & $97^{d}$ \\
\hline $\mathrm{Ph}-p$-Me & 4d & $95(\mathrm{C})$ & 5d & $93^{\mathrm{d}}$ \\
\hline $\mathrm{Ph}-p$-OMe & $4 e$ & $83(\mathrm{C})$ & $5 e$ & $98^{\mathrm{d}}$ \\
\hline $\mathrm{Ph}-p$-SMe & $4 f$ & $96(\mathrm{D})$ & $5 f$ & $100^{\mathrm{e}}$ \\
\hline $\mathrm{Ph}-3,5$-di-OMe & $4 g$ & 94 (D) & $5 g$ & $100^{\mathrm{e}}$ \\
\hline 2-Naphthyl & $4 h$ & $94(\mathrm{C}), 99$ (D) & $5 \mathrm{~h}$ & $78^{\mathrm{d}}, 100^{\mathrm{e}}$ \\
\hline 2-Naphthyl-6-OMe & $4 \mathbf{i}$ & 99 (D) & $5 \mathbf{i}$ & $100^{\mathrm{e}}$ \\
\hline 2-Naphthyl-6-OTIPS & $4 \mathbf{j}$ & 93 (D) & & \\
\hline 2-Naphthyl-6-OH & $4 k^{f}$ & 99 & $5 \mathbf{k}$ & $100^{\mathrm{e}}$ \\
\hline 9-Phenanthrenyl & 41 & $96(\mathrm{D})$ & 51 & $100^{\mathrm{e}}$ \\
\hline 1,3-Benzodioxol-5-yl & $4 m$ & 95 (D) & $5 \mathrm{~m}$ & $100^{\mathrm{e}}$ \\
\hline $\begin{array}{l}\text { 2,3-Dihydrobenzo-1,4- } \\
\text { dioxin-6-yl }\end{array}$ & $4 n$ & 89 (D) & $5 n$ & $100^{\mathrm{e}}$ \\
\hline 2-Benzo[b]furanyl & 40 & 60 (D) & 50 & $90^{\mathrm{e}}$ \\
\hline 2-Benzo $[b]$ thienyl & $4 p$ & $54(\mathrm{D})$ & $5 p$ & $85^{\mathrm{e}}$ \\
\hline 2-Benzothiazolyl & $4 q$ & 62 (D) & $5 q$ & $68^{\mathrm{d}}$ \\
\hline 2-Indolyl & $4 r$ & 64 (D) & $5 r$ & $58^{\mathrm{d}}$ \\
\hline 3-Indolyl & $4 s$ & 60 (D) & $5 s$ & $55^{\mathrm{d}}$ \\
\hline
\end{tabular}

${ }^{a}$ Method C: ${ }^{33}$ exo-glucal $(0.3 \mathrm{mmol}), \alpha$-chloroaldoxime (3 to 5 eq.), $\mathrm{CH}_{2} \mathrm{Cl}_{2}(5 \mathrm{~mL})$, overnight addition of $\mathrm{NEt}_{3}$

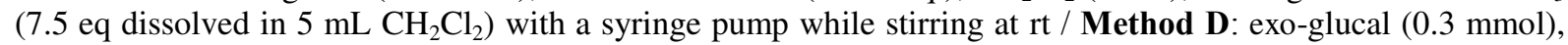
aldoxime (2 eq.) in THF $(10 \mathrm{~mL})$, overnight addition of $\mathrm{NaOCl}_{\mathrm{aq}} 9^{\circ} \mathrm{Chl}(5 \mathrm{~mL})$ with a syringe pump while stirring at rt.

${ }^{\mathrm{b}}$ Deacetylation by the Zemplén conditions ( $\left.\mathrm{MeONa}, \mathrm{MeOH}\right)$.

${ }^{c}$ n.a. $=$ not applicable - Heteroaromatisation led to a ring-opened product.

${ }^{\mathrm{d}}$ Purification by column chromatography.

${ }^{\mathrm{e}}$ Concentration to dryness.

${ }^{\mathrm{f}}$ Prepared from $\mathbf{4 j}$ upon treatment with TBAF. 
Enzyme inhibition

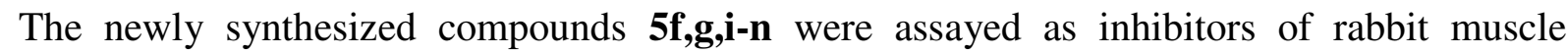
glycogen phosphorylase $\mathrm{b}(\mathrm{RMGPb})$ and the obtained $\mathrm{IC}_{50}$ values together with the $\mathrm{K}_{\mathrm{i}}$ data of the previous series $\mathbf{5 b - e , h}$ are presented in Table 2. Depending on the mono- or polycyclic nature as well as the substitution pattern of the aromatic groups (Ar) the strength of inhibition varied ranging from 1 to $800 \mu \mathrm{M}$. The best inhibitors in both series displayed a 2-naphthyl moiety (5h and $\mathbf{5 k})$. Changing the 6-OH substituent of the naphthyl group in $\mathbf{5 k}$ to a methoxy (5i) resulted in a weaker inhibitory potency suggesting that the 6-OH probably participates in a favourable H-bond. Increasing the size of the aromatic moiety by the annelation of a further ring as in $\mathbf{5 l}$ (phenanthrenyl) or changing its nature to partly aromatic $(\mathbf{5 m}, \mathbf{n})$ made significantly less efficient inhibitors showing that the planar aromatic substituent of proper size and orientation is very important for the binding. This is further corroborated by the benzolog heterocycles 5o-s, which were also less efficient than the 2-naphthyl derivatives. The position of apolar substituents on a phenyl ring proved also decisive since a monosubstitution in the 4-position strengthened (compare 5d-f to 5c) while a 3,5-disubstitution (5g) weakened the inhibition. The case of the 4-nitrophenyl group (5b) was discussed earlier. ${ }^{33}$

Table 2: RMGP $b$ inhibition of glucose-based spiro-isoxazolines $\mathbf{5 b - i , k - s}$

\begin{tabular}{|l|l|c|c|}
\hline \multirow{2}{*}{$\mathrm{Ar}=$} & Compounds & \multicolumn{2}{l|}{$\begin{array}{l}\text { Inhibition } \\
{[\mu \mathrm{M}]}\end{array}$} \\
\cline { 3 - 4 } & & $\mathrm{IC}_{50}$ & $K_{\mathrm{i}}$ \\
\hline $\mathrm{Ph}-4-\mathrm{NO}_{2}$ & $\mathbf{5 b}$ & & $92.5^{33}$ \\
\hline $\mathrm{Ph}$ & $\mathbf{5 c}$ & & $19.6^{33}$ \\
\hline $\mathrm{Ph}-4-\mathrm{Me}$ & $\mathbf{5 d}$ & & $7.9^{33}$ \\
\hline $\mathrm{Ph}-4-\mathrm{OMe}$ & $\mathbf{5 e}$ & & $6.6^{33}$ \\
\hline $\mathrm{Ph}-4-\mathrm{SMe}$ & $\mathbf{5 f}$ & $5.6 \pm 0.7$ & \\
\hline $\mathrm{Ph}-3,5-$ di-OMe & $\mathbf{5 g}$ & $324.7 \pm 24.1$ & \\
\hline 2-Naphthyl & $\mathbf{5 h}$ & & $0.63^{33}$ \\
\hline 2-Naphthyl-6-OMe & $\mathbf{5 i}$ & $27.7 \pm 1.7$ & \\
\hline 2-Naphthyl-6-OH & $\mathbf{5 k}$ & $1.54 \pm 0.08$ & \\
\hline 9-Phenanthrenyl & $\mathbf{5 l}$ & $80.5 \pm 6.6$ & \\
\hline 1,3-Benzodioxol-5-yl & $\mathbf{5 m}$ & $81.3 \pm 5.4$ & \\
\hline 2,3-Dihydrobenzo-1,4-dioxin-6-yl & $\mathbf{5 n}$ & $13.3 \pm 0.3$ & \\
\hline 2-Benzo[b]furanyl & $\mathbf{5 0}$ & $25.0 \pm 2.3$ & \\
\hline
\end{tabular}




\begin{tabular}{|l|l|c|l|}
\hline 2-Benzo $[b]$ thienyl & $\mathbf{5 p}$ & $10.0 \pm 0.8$ & \\
\hline 2-Benzothiazolyl & $\mathbf{5 q}$ & $6.1 \pm 0.5$ & \\
\hline 2-Indolyl & $\mathbf{5 r}$ & $280.0 \pm 5.5$ & \\
\hline 3-Indolyl & $\mathbf{5 s}$ & $800.0 \pm 11.5$ & \\
\hline
\end{tabular}

In vitro pharmacological evaluations

Following the results of the kinetic studies, and in view of evaluating further their inhibitory properties, seven O-unprotected sugar-derived spiro-isoxazolines (5f-h, k-n spanning over the whole inhibition range observed) and the acetylated analogue $\mathbf{4 h}$ have been selected for in vitro evaluation with rat and human hepatocytes in primary cultures. Hepatocytes in primary culture were isolated in situ from rat liver for rat hepatocytes or from surgical liver pieces for human hepatocytes (see Table S1). 1,4-Dideoxy-1,4-imino-D-arabinitol (DAB), known as a highly potent in vitro GP inhibitor ${ }^{55}\left(\mathrm{~K}_{\mathrm{i}}=400 \mathrm{nM}\right)$, was selected as the reference compound based on its validated in vivo activity in a GP-dependent glycaemia study. ${ }^{55-58}$ A screening in primary rat hepatocytes for glucose release after glucagon stimulation was performed. Compounds have also been evaluated in human hepatocytes by measuring both glucose release and intracellular glycogen to evaluate species specificity.

Among the seven unprotected compounds (5f-h, k-n), five (5f, 5g, 5l, 5m, 5n) displayed half-maximal inhibitory concentration $\left(\mathrm{IC}_{50}\right)$ superior to $100 \mu \mathrm{M}$ both in rat and human hepatocytes both for glucose release (Table 3) and for intracellular glycogen content (Table 4, human hepatocytes only). Due to their poor properties, these compounds were not evaluated further. Compounds $\mathbf{5 h}$ and $\mathbf{5 k}$, which displayed $\mathrm{IC}_{50}$ values in the micromolar range appeared as two interesting candidates with highly similar inhibitory potencies measured both in rat and human models. In human hepatocyte cultures, $\mathrm{IC}_{50}$ calculated for glucose release (product of GP-mediated glycogen depolymerization) or intracellular glycogen content (substrate of GP-mediated glycogen depolymerization) are similar (13 to 22 
$\mu \mathrm{M}$, Tables 3\&4), proving that compounds $\mathbf{5 h}$ and $\mathbf{5 k}$ targeted glycogenolysis via GP inhibition in the cellular model.

Acetate protecting groups are usually cleaved by ubiquitous esterases and the higher lipophilicity of the molecule would facilitate cell permeation. ${ }^{59-62}$ The acetylated compound 4h was also evaluated as a prodrug of the O-unprotected derivative $\mathbf{5 h}$. To our delight, lower $\mathrm{IC}_{50}$ values were consistently recorded for compound $\mathbf{4 h}$ in comparison to the O-unprotected derivative 5h. This observation pointed to better species specificity for the acetylated compound $\mathbf{4 h}$ than for compound $\mathbf{5 h}$. This lack of species difference was established for two indole site inhibitors against recombinant rat and human liver $\mathrm{GPa}^{63}$ and also for another indole site inhibitor studied in rat and human liver cells. ${ }^{64}$

Table 3: In vitro $\mathrm{IC}_{50}$ for the acetylated spiro-isoxazoline $\mathbf{4 h}$ and unprotected analogues $\mathbf{5 f -}$ h,k-n based on glucose release after glucagon stimulation in rat and human hepatocytes in primary cultures

\begin{tabular}{|l|l|l|l|}
\hline \multirow{2}{*}{ Ar $=$} & \multirow{2}{*}{ Compound } & \multicolumn{2}{l|}{$\begin{array}{l}\text { Glucose release } \\
\mathbf{I C}_{\mathbf{5 0}}(\boldsymbol{\mu M})^{\mathbf{a}}\end{array}$} \\
\cline { 3 - 4 } & & Rats & Humans \\
\hline O-Acetylated derivative & & & \\
\hline 2-Naphthyl & $\mathbf{4 h}$ & $13.58 \pm 0.44$ & $2.50 \pm 2.68$ \\
\hline O-Unprotected derivatives & & & \\
\hline Ph-4-SMe & $\mathbf{5 f}$ & $>100$ & $>100$ \\
\hline Ph-3,5-di-OMe & $\mathbf{5 g}$ & $>100$ & $>100$ \\
\hline 2-Naphthyl & $\mathbf{5 h}$ & $36.00 \pm 12.93$ & $19.95 \pm 4.90$ \\
\hline 2-Naphthyl-6-OH & $\mathbf{5 k}$ & $30.07 \pm 2.78$ & $22.16 \pm 3.74$ \\
\hline 9-Phenanthrenyl & $\mathbf{5 l}$ & $>100$ & $>100$ \\
\hline 1,3-Benzodioxol-5-yl & $\mathbf{5 m}$ & $>100$ & $>100$ \\
\hline 2,3-Dihydrobenzo-1,4-dioxin-6-yl & $\mathbf{5 n}$ & $>100$ & $>100$ \\
\hline
\end{tabular}

${ }^{\text {a }} \mathrm{IC}_{50}$ values are average triplicate measurements for three (4h and $\left.\mathbf{5 h}\right)$ to five $(\mathbf{5 k})$ human hepatocyte cultures (see supporting information) and average for three to five measurements in rat hepatocytes cultures. 
Table 4: In vitro $\mathrm{IC}_{50}$ for the acetylated spiro-isoxazoline $\mathbf{4 h}$ and unprotected analogues $\mathbf{5 f}$ h,k-n based on intracellular glycogen content after glucagon stimulation of human hepatocytes in primary cultures

\begin{tabular}{|l|l|l|}
\hline Ar $=$ & Compound & $\begin{array}{l}\text { Intracellular glycogen } \\
\mathbf{I C}_{\mathbf{5 0}}(\boldsymbol{\mu M})^{\mathbf{a}}\end{array}$ \\
\cline { 3 - 3 } & & Humans \\
\hline O-Acetylated derivative & \\
\hline 2-Naphthyl & $\mathbf{4 h}$ & $2.38 \pm 2.64$ \\
\hline O-Unprotected derivatives & & \\
\hline Ph-4-SMe & $\mathbf{5 f}$ & $>100$ \\
\hline Ph-3,5-di-OMe & $\mathbf{5 g}$ & $>100$ \\
\hline 2-Naphthyl & $\mathbf{5 h}$ & $14.18 \pm 8.16$ \\
\hline 2-Naphthyl-6-OH & $\mathbf{5 k}$ & $13.78 \pm 12.74$ \\
\hline 9-Phenanthrenyl & $\mathbf{5 l}$ & $>100$ \\
\hline 1,3-Benzodioxol-5-yl & $\mathbf{5 m}$ & $>100$ \\
\hline 2,3-Dihydrobenzo-1,4-dioxin-6-yl & $\mathbf{5 n}$ & $>100$ \\
\hline
\end{tabular}

${ }^{\mathrm{a}} \mathrm{IC}_{50}$ values are average triplicate measurements for three (4h and $\mathbf{5 h}$ ) to five $(\mathbf{5 k})$ human hepatocyte cultures (see supporting information)

The analysis of the concentration-response curves for glucose release (Figure 2) and intracellular glycogen content (Figure 3) allowed for a comparison against DAB. Both Ounprotected derivatives $\mathbf{5 h}$ and $\mathbf{5 k}$ necessitated slightly higher concentrations in comparison to $\mathrm{DAB}$ to obtain $50 \%$ inhibition. Nevertheless, such concentrations were still in agreement with potential pharmacological applications. However, the acetylated compound $\mathbf{4 h}$ performed similarly to DAB in such in vitro assays. 

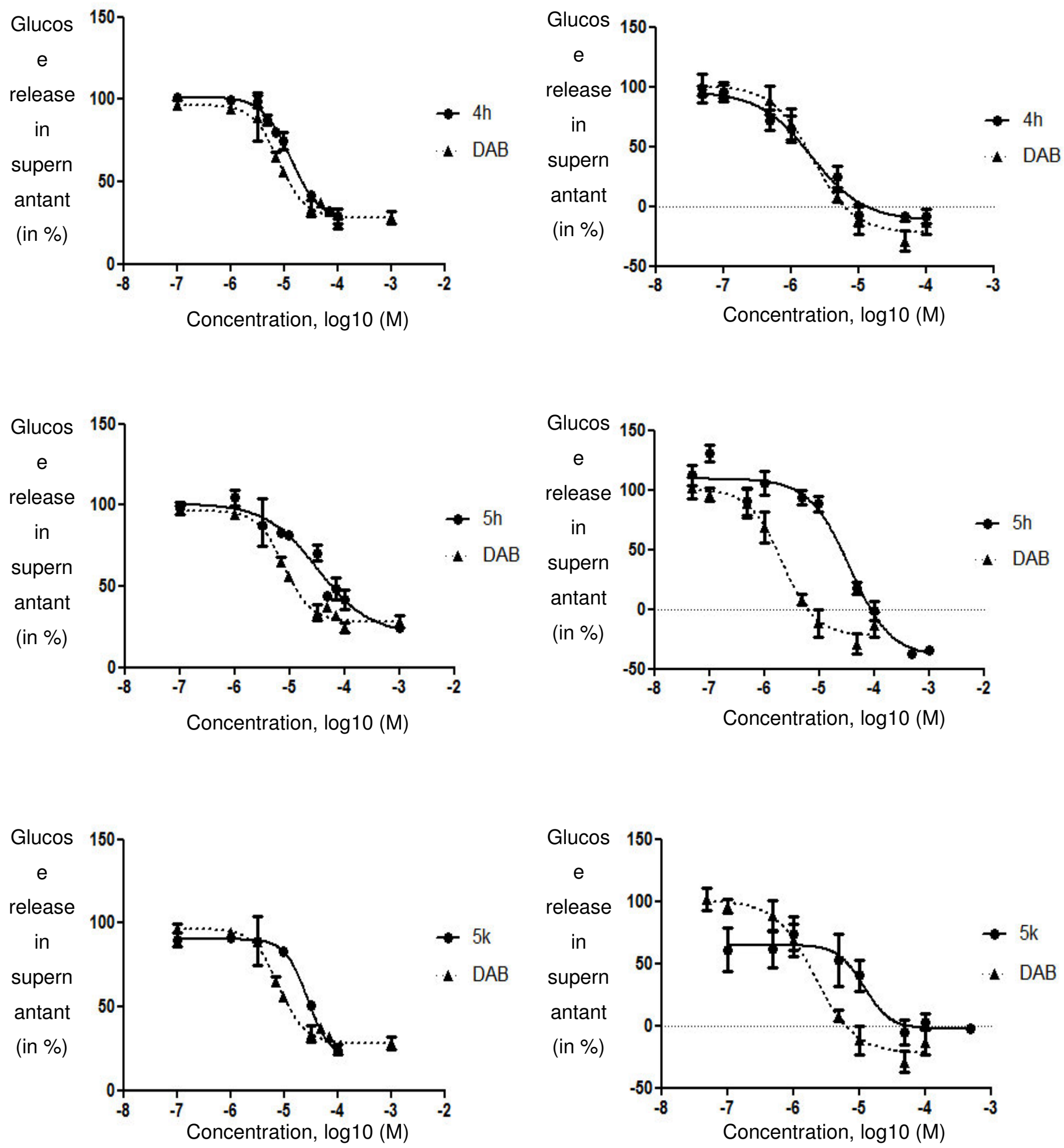

Figure 2: Glucose release from rat and human hepatocytes after glucagon stimulation in vitro

measured in the presence of compounds $\mathbf{4 h}, \mathbf{5 h}$, and $\mathbf{5 k}$ versus $\mathrm{DAB}$ as the reference compound. Compounds with $\mathrm{IC}_{50}>100 \mu \mathrm{M}$ are not presented. 



Figure 3: Intracellular glycogen content in human hepatocytes after glucagon stimulation in vitro measured in the presence of compounds $\mathbf{4 h}, \mathbf{5 h}$, and $\mathbf{5 k}$ versus DAB as the reference compound. Compounds with $\mathrm{IC}_{50}>100 \mu \mathrm{M}$ are not presented.

In vivo pharmacological evaluations

The glucose-lowering effect was evaluated in vivo with the glucagon challenge test in the Zucker fa/fa rat model for the two best compounds $\mathbf{5 h}$ and $\mathbf{5 k}$ identified above (Tables $3 \& 4$ ). This rat model, characterized by hyperphagia and insulin resistance with hyperinsulinemia, was chosen because the hepatic glycogen content is high.

In this test, glucagon $(200 \mu \mathrm{g} / \mathrm{kg}$, in a single subcutaneous "SC" administration) was used as hyperglycemic agent. The pharmacological effect of compounds $\mathbf{5 h}$ and $\mathbf{5 k}$ was 
evaluated while the acetylated compound $\mathbf{4 h}$ could not be tested in vivo because of poor water solubility. Each compound was given orally in a single administration. Compound $\mathbf{5 k}$ showed no dose-dependent effect (data not shown). The results of the unprotected compound $\mathbf{5 h}$ are presented in Figure 4.

The kinetics of liver glucose output (Figure 4A) and the corresponding areas under the curves (AUC) for 45 min (Figure 4B) revealed a dose-dependent decrease in liver glucose production in the range of 7.5 to $30 \mathrm{mg} / \mathrm{kg}$, reaching a plateau of approximately $30 \%$ reduction at $30 \mathrm{mg} / \mathrm{kg}$ (Figure $4 \mathrm{~B}$, $* * \mathrm{p}<0.01$ for $30 \mathrm{mg} / \mathrm{kg}$ and $* * * \mathrm{p}<0.001$ for $60 \mathrm{mg} / \mathrm{kg}$ ). This effect on liver glucose output may be relevant for therapeutic applications since the rate of endogenous glucose production is elevated in type 2 diabetes. ${ }^{65}$ 


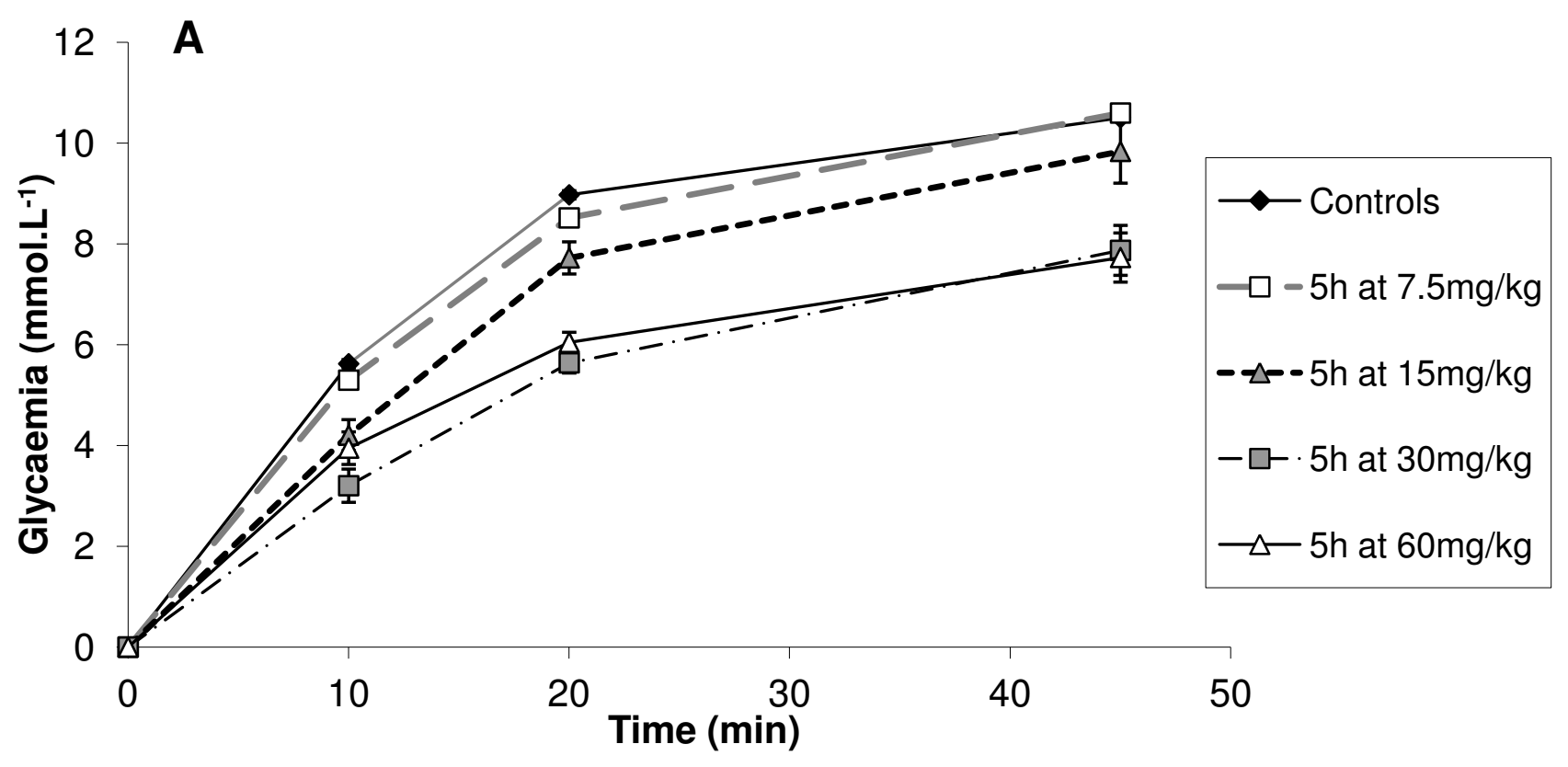

B

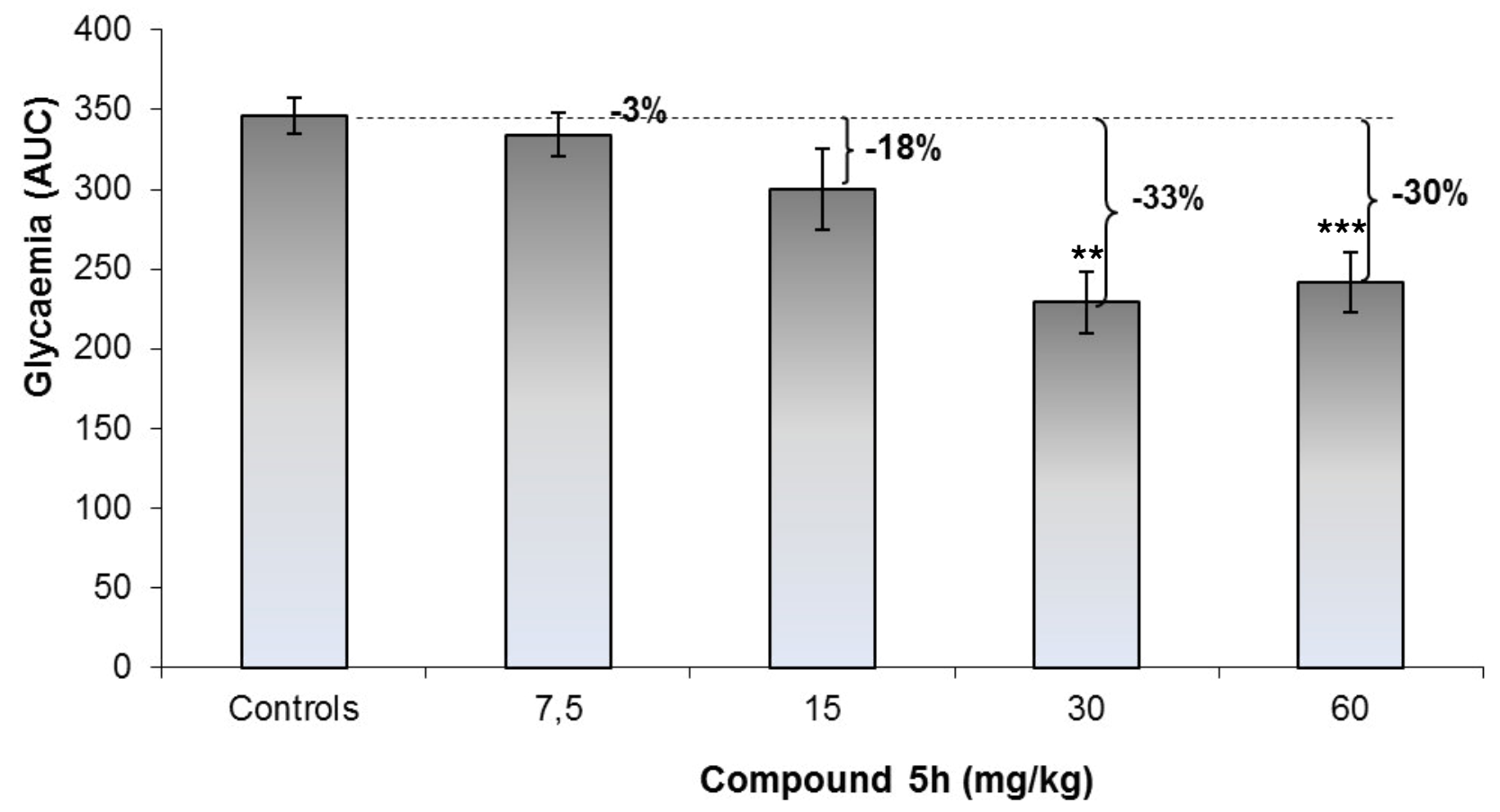

Figure 4: Hepatic glucose production of the unprotected compound $\mathbf{5 h}$ obtained in Zucker fa/fa rats in acute in vivo glucagon challenge. (A) Kinetics of glucose output for 45 minutes after acute glucagon administration in mmol/L. (B) Area Under the Curves corresponding to glucose release for 45 minutes after acute glucagon administration. 
A subchronic oral administration was performed for compound $\mathbf{5 h}$. The dose chosen was the first significantly effective dose in the acute in vivo glucagon challenge test, namely $30 \mathrm{mg} / \mathrm{kg}$. A glucagon challenge test was performed after 4 days of treatment. A reduction of hepatic glucose production of approximately 19\% (* p<0.05) was observed (Figure 5A-B), which is accompanied by a reduced insulin output (Figure 5C). Furthermore, in spite of the subchronic treatment, hepatic glucose production was not further reduced, indicating that the activity of glycogen phosphorylase was preserved. 


Figure 5: Plasma glucose and insulin concentrations of the unprotected compound $\mathbf{5 h}$ obtained in Zucker fa/fa rats subjected to in vivo glucagon challenge after subchronic administrations. (A) Kinetics of glucose output for 45 minutes after acute glucagon administration in mmol/L. (B) Area Under the Curves corresponding to glucose release for 45 minutes after acute glucagon administration. (C) Insulin concentrations for 45 minutes after acute glucagon administration in $\mathrm{ng} / \mathrm{mL}$. Plasma glucose and insulin concentrations were expressed as variations (delta), meaning that the basal value of glycaemia or insulinemia was subtracted for each individual value and for each rat.

After 6 days of treatment at $30 \mathrm{mg} / \mathrm{kg}$ of compound $\mathbf{5 h}$, an oral glucose tolerance test (OGTT, $3 \mathrm{~g} / \mathrm{kg}$ ) was performed (Figure 6). The results are expressed in delta, it means that the basal value of glycaemia or insulinemia is subtracted for each individual value and for each rat. The areas under the curve (AUCs) for $60 \mathrm{~min}$ were established. There is a significant decrease in insulinemia $(* * * \mathrm{p}<0.001)$ in the $\mathbf{5 h}$ treated group comparatively to controls, whereas glycaemia was not different between the two groups, which may be indicative of an improved insulin sensitivity in this hyperinsulinemic insulin-resistant rat model. 


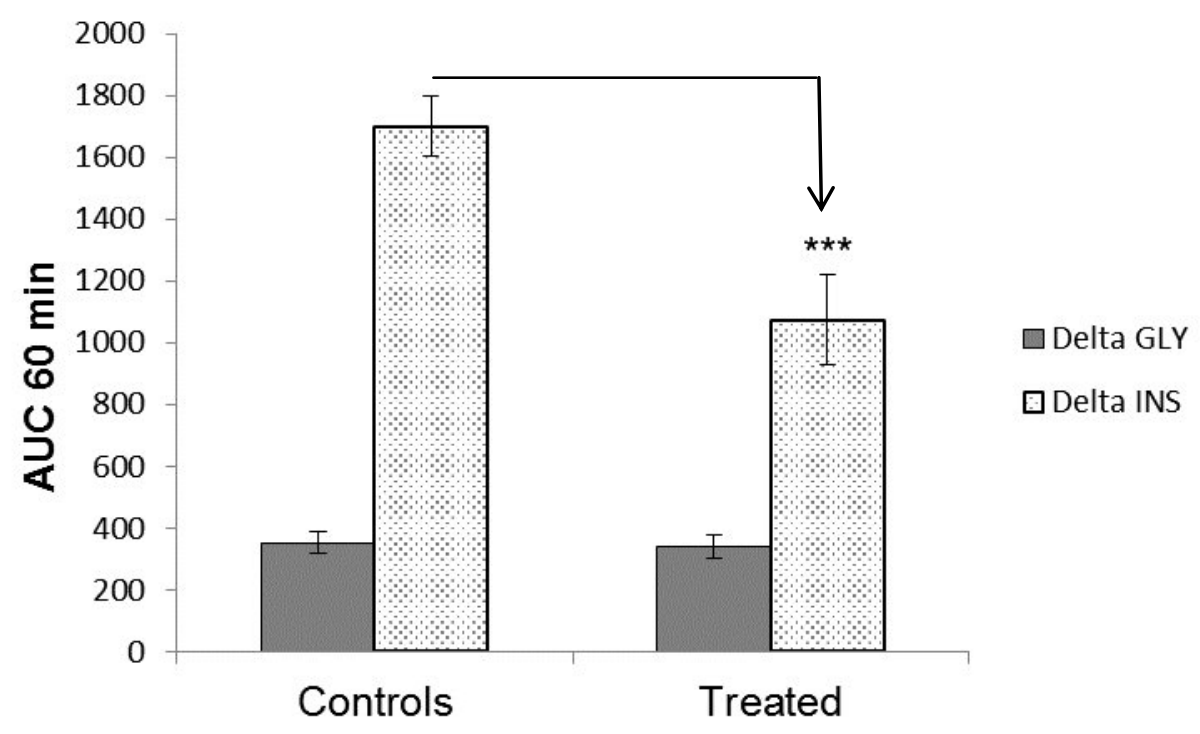

Figure 6: AUC 60 min for delta glycaemia and delta insulinemia measured in Zucker fa/fa rats in an oral glucose tolerance test (OGTT) after 6 days of treatment with compound $\mathbf{5 h}$. Plasma glucose and insulin concentrations were expressed as variations (delta), meaning that the basal value of glycaemia or insulinemia was subtracted for each individual value and for each rat.

In the present study, we have characterized in vitro and in vivo pharmacological effects of glucose-based spiro-isoxazolines as novel potent glycogen phosphorylase inhibitors. Spiro-isoxazolines such as acetylated compound $\mathbf{4 h}$, and the O-unprotected analogues $\mathbf{5 h}$ and $\mathbf{5 k}$, reduced glucagon-stimulated glucose output by inhibiting glycogenolysis in rat and human hepatocytes (Table 3, Figure 2).

The potencies of the different compounds for inhibition of glucose output are rather similar between rat and human cells, indicating the absence of species specificity (Table 3 ). Freeman et al. ${ }^{63}$ have established that there was no species difference in the potencies of GPi688 and GPi819, two indole site inhibitors, against recombinant rat and human liver phosphorylase a. Moreover, this lack of species specificity for liver glycogen phosphorylase is consistent with data reported for the indole site inhibitor CP-91149 in rat and human liver 
cells. ${ }^{64}$ Compound $\mathbf{5 h}$ was active in vivo in the Zucker fa/fa rat model of insulin resistance, dose-dependently decreasing hepatic glucose output to a maximal 30\% inhibition (Figure 4). This effect may be relevant for therapeutic application since the rate of endogenous glucose production is elevated in type 2 diabetes. ${ }^{65}$ Indeed, hepatic glucose production tends to normalize towards the values usually obtained in Wistar normal rat

The moderate level of inhibition of glycogen phosphorylase contrasts with the complete suppression of glucagon-induced glucose output observed in the presence of DAB. ${ }^{58}$ The fact that compound $\mathbf{5 h}$ does not completely suppress glycogen phosphorylase activity may be of interest in limiting potential unwanted effects. In particular, the lack of tissuespecificity of GP inhibitors between liver and muscle glycogen phosphorylase isoforms could lead to impairment of exercise-mediated metabolism of muscle glycogen. Maintaining a certain level of activity may limit this risk, although the selection of a liver-specific inhibitor would be preferred for long-term therapy. ${ }^{66}$

Hepatic glucose production was not further reduced after repeated administrations of GP inhibitors, indicating that, although at a lower level, the activity of GP was preserved and might limit the risk of hypoglycaemia (Figure 5). After the short-term repeated administration of $\mathbf{5 h}$ in the insulin-resistant rat model, the results of the oral glucose tolerance test (OGTT) suggested that insulin sensitivity might be improved in treated animals (Figure 6).

Glucopyranosylidene-spiro-thiohydanthoin (TH) was reported as a potent GP inhibitor in vivo using diabetic rat models (streptozotocin rat and Zucker Diabetic Fatty rat). ${ }^{27,31} \mathrm{TH}$ was efficient at low dose $(50 \mu \mathrm{M})$ and induced lower plasma glucose levels and restored hepatic glycogen content. In addition, TH was also shown to restore whole body insulin sensitivity in streptozotocin-treated rats. ${ }^{67}$ In a parallel study from the same group, N-(3,5dimethyl-benzoyl)-N'-( $\beta$-D-glucopyranosyl)urea was evaluated in vivo and improved glucose 
tolerance in diabetic mice models resulting from higher hepatic glucose uptake. ${ }^{32}$ Each of these studies used glucose-based GP inhibitors targeting the catalytic site of the enzyme as proven by X-ray crystallographic studies. Taken together, these results and the present study described herein suggest that targeting the catalytic site of glycogen phosphorylase with glucose-based spiro-isoxazolines may be a promising strategy to control the dysfunctional glycemic regulation characterizing type 2 diabetes. Further research efforts are encouraged to validate this approach and evaluate its benefice-to-risk balance.

\section{Conclusion}

Type 2 diabetes is a major public health problem and design of glycogen phosphorylase inhibitors appears as a promising target for a better control of hyperglycaemia. Glucopyranosylidene-spiro-isoxazolines have been recently identified as potent GP inhibitors. Their preparation from the corresponding methylene exo-glycals and nitrile oxides was limited by the availability of the $\alpha$-chlorooximes as precursours of these dipoles. The present synthetic strategy utilizes the readily available oximes and their oxidation is realized in situ with bleach, thus giving access to additional glucopyranosylidene-spiro-isoxazolines previously not attainable. This mild and direct procedure appeared to be applicable to a broad range of substrates. The GP inhibitors exhibited $\mathrm{IC}_{50}$ values in the micromolar range and a selection were further evaluated in vitro using rat and human hepatocytes and the most promising compounds were investigated in Zucker fa/fa rat model in acute and sub-chronic assays. The 2-naphthyl substituted glucopyranosylidene-spiro-isoxazoline was the best compound identified in this study and lowered glucose levels in blood of nearly $33 \%$ at a dose of $30 \mathrm{mg} / \mathrm{kg}$, indicating that glucose-based spiro-isoxazolines can be considered as antihyperglycemic agents in the context of type 2 diabetes. The present study is one of the few in 
vivo investigations for the glucose-based GP inhibitors and provides unprecedented data in animal models for such drug candidates.

\section{Acknowledgements}

Financial supports from CNRS and Hungarian Academy of Sciences (PICS 2008-2010 $\mathrm{n}^{\circ}$ 4576), University Claude Bernard Lyon 1 and the French Agence Nationale de la Recherche (support of the ANR project GPdia ${ }^{\circ}$ ANR-08-BLAN-0305 for both expenses and salaries of Sophie Balzarin, Jérémy Leroy and David Goyard) are gratefully acknowledged. Dr F. Albrieux, C. Duchamp and N. Henriques are gratefully acknowledged for mass spectrometry analyses. Synthetic and enzymological work in Debrecen was supported by the University of Debrecen, the Hungarian Scientific Research Fund (OTKA 109450) and the TÁMOP 4.2.1/B-09/1/KONV-2010-0007 project co-financed by the European Union and the European Social Fund. Tibor Docsa is a recipient of Bolyai Fellowship from the Hungarian Academy of Sciences. Kinetic studies performed in Athens were supported by the FP7 Capacities coordination and support action REGPOT-2009-1-No 245866 'ARCADE'.

Supplementary information : Synthetic general methods and procedures to the new oximes $\mathbf{1 j}, \mathbf{1 l}$ and the analytical data for the acetylated spiro-isoxazolines $\mathbf{4 a}, \mathbf{4 f}-\mathbf{s}$, the O-unprotected spiro-isoxazolines (5f-i, 5k-s), an O-unprotected isoxazolyl-pentaol (5a': ${ }^{1} \mathrm{H}$ NMR only). 


\section{EXPERIMENTAL SECTION}

\section{SYNTHESES}

\section{General procedure A1 for the synthesis of aromatic aldoximes}

To a suspension of aldehyde $(30 / 35 \mathrm{mmol})$ in ethanol $(50 \mathrm{~mL})$ was added $\mathrm{NH}_{2} \mathrm{OH} \cdot \mathrm{HCl}(2 \mathrm{eq})$ and $\mathrm{NaOH}$ pellets $(1.8 \mathrm{eq})$. The suspension was stirred at $80^{\circ} \mathrm{C}$ for $4 \mathrm{~h}$ and concentrated in vacuo. The crude product was extracted in EtOAc $(200 \mathrm{~mL})$. The organic layer was washed with $1 \mathrm{~N} \mathrm{HCl}(2 \times 200 \mathrm{~mL})$, water $(4 \times 200 \mathrm{~mL})$, dried $\left(\mathrm{MgSO}_{4}\right)$ and concentrated in vacuo. If TLC showed impurities, the solid was washed with a minimum of cold $\mathrm{Et}_{2} \mathrm{O}$ to afford the aldoxime as a white powder.

\section{General procedure A2 for the synthesis of aromatic aldoximes ${ }^{68}$}

An aldehyde $(3.24 \mathrm{mmol})$ was dissolved in $\mathrm{EtOH}(12 \mathrm{~mL})$, then a solution of $\mathrm{NH}_{2} \mathrm{OH} \cdot \mathrm{HCl}$ (360 mg, $5.18 \mathrm{mmol})$ and $\mathrm{Na}_{2} \mathrm{CO}_{3}(247 \mathrm{mg}, 2.33 \mathrm{mmol})$ in water $(3 \mathrm{~mL})$ was added, and the mixture was boiled at reflux temp for $20 \mathrm{~min}$. Saturated aqueous $\mathrm{NaCl}$ solution $(30 \mathrm{~mL})$ was added, and the mixture was extracted by EtOAc $(2 \times 20 \mathrm{~mL})$. The combined organic layers were dried $\left(\mathrm{MgSO}_{4}\right)$ and evaporated to give the expected aldoxime which was used without further purification.

\section{General procedure B for the synthesis of aromatic chloroximes/hydroximoyl chlorides}

To a solution of aldoxime 1b-e,h,o-s $(5.0 \mathrm{mmol}, 1 \mathrm{eq})$ in dry DMF (30 mL) was added NCS (1.2 eq) in portions over 2 min while $\mathrm{HCl}$ gas was bubbled in the solution. The mixture was stirred at $\mathrm{rt}$ for $2 \mathrm{~h}$, diluted with EtOAc $(150 \mathrm{~mL})$, washed with water $(3 \times 100 \mathrm{~mL})$, and brine $(3 \times 100 \mathrm{~mL})$. The organic layer was dried over $\mathrm{MgSO}_{4}$ and concentrated in vacuo. If TLC of the crude product showed impurities, it was dissolved in a minimum volume of $\mathrm{CH}_{2} \mathrm{Cl}_{2}$. Precipitation with petroleum ether and filtration afforded hydroximoyl chlorides $\mathbf{2 b - e , h}$ as solids. 
General procedure $C$ for the synthesis of spiro-isoxazolines $4 b$-e,h with $\alpha$-chloroximes 2b-e,h

A solution of $\mathrm{Et}_{3} \mathrm{~N}$ ( $3 \mathrm{M}$ in $\mathrm{CH}_{2} \mathrm{Cl}_{2}$ ) was added slowly with a syringe pump ( $\left.\sim 16 \mathrm{~h}\right)$ to a solution of exo-glucal 3A (1 mmol) and hydroximoyl chlorides $2 \mathbf{b}-\mathbf{e}, \mathbf{h}$ (3 to 5 eq) in dry $\mathrm{CH}_{2} \mathrm{Cl}_{2}(30 \mathrm{~mL})$. The mixture was stirred at $\mathrm{rt}$ overnight and concentrated in vacuo. The crude product was purified by chromatography on silica gel (petroleum ether/EtOAc 7:3) to afford spiro-isoxazolines $\mathbf{4 b - e , h}$.

\section{General procedure D for the synthesis of spiro-isoxazolines with oximes $2 \mathbf{2 a}, \mathbf{f}-\mathbf{j}, \mathbf{l}-\mathbf{s}$}

From exo-glucal 3A: An aqueous solution of $\mathrm{NaOCl}\left(5 \mathrm{~mL}, 9^{\circ} \mathrm{Chl}\right.$ prepared from a $36^{\circ} \mathrm{Chl}$ commercial solution, diluted 4 times) was added slowly with a syringe pump ( $16 \mathrm{~h})$ at rt to a solution of methylene exo-glycal 3A (100 mg, $0.29 \mathrm{mmol})$ and aldoxime $(0.58 \mathrm{mmol}, 2 \mathrm{eq})$ in THF $(10 \mathrm{~mL})$. The mixture was diluted with water $(10 \mathrm{~mL})$ and extracted with $\mathrm{CH}_{2} \mathrm{Cl}_{2}(3 \times 20$ $\mathrm{mL}$ ). The organic layer was dried over $\mathrm{MgSO}_{4}$ and concentrated in vacuo. The crude product was purified by silica gel chromatography (petroleum ether/EtOAc, 7:3) to afford the

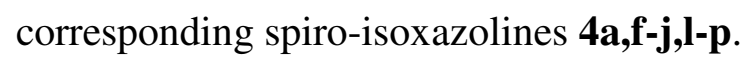

From exo-glucal 3B: An aqueous solution of $\mathrm{NaOCl}(0.2 \mathrm{M}, 20 \mathrm{~mL})$ was added slowly with a syringe pump ( $16 \mathrm{~h})$ to a solution of exo-glucal 3B $(0.262 \mathrm{mmol})$ and carbaldehyde oxime 2q-s $(1.1 \mathrm{eq})$ in THF $(4 \mathrm{~mL})$. The reaction was diluted with EtOAc $(30 \mathrm{~mL})$ and the aqueous layer was extracted with EtOAc $(2 \times 30 \mathrm{~mL})$. The collected organic layer was washed with brine $(20 \mathrm{~mL})$, dried $\left(\mathrm{MgSO}_{4}\right)$, filtered and evaporated under reduced pressure. The residue was purified by flash chromatography (petroleum ether/EtOAc, 3:2) to afford the desired spiro-isoxazolines $\mathbf{4 q - s}$.

\section{General procedure $\mathrm{E}$ for the Zemplén deacetylation}

Commercially available powdered $\mathrm{MeONa}(0.4$ eq) was added to a suspension of acylated spiro-isoxazoline $(\sim 0.2 \mathrm{mmol})$ in dry $\mathrm{MeOH}(5 \mathrm{~mL})$. If the acylated substrate was not soluble 
in $\mathrm{MeOH}, \mathrm{CH}_{2} \mathrm{Cl}_{2}$ was added in order to reach reasonable solubility. After stirring at $\mathrm{rt}$ until TLC showed completion of the reaction (15 to $20 \mathrm{~h}$ ), the mixture was neutralized with Amberlite IR 120 resin, filtered and concentrated in vacuo to afford the corresponding Ounprotected spiro-isoxazoline.

\section{Kinetic evaluation of compounds ${ }^{69-70}$}

Evaluation of the inhibitory potency of compounds on RMGPb (isolated from rabbit skeletal muscle as described previously ${ }^{71}$ using 2-mercaptoethanol) was performed in vitro in the direction of glycogen synthesis at $30^{\circ} \mathrm{C}$ in the presence of $2 \mathrm{mM}$ glucose-1-phosphate, $1 \mathrm{mM}$ AMP. Different inhibitor concentrations varying from $5 \mu \mathrm{M}$ to $1 \mathrm{mM}$ were tested and the phosphate release was evaluated according to reported methods.

\section{PHARMACOLOGICAL EVALUATIONS}

\section{Rat and human hepatocytes isolation}

Male Wistar rats (160-220 g) were anaesthetized with sodium pentobarbital administered intraperitoneally. Hepatocytes were isolated from rats fed ad lib using a two-step perfusion technique. ${ }^{72}$ Cell viability, assessed by Trypan Blue exclusion, was consistently greater than 75\%. Cells were seeded on collagen-coated 12-well plates in basal medium (William's E containing $11.1 \mathrm{mM}$ glucose, $100 \mathrm{U} / \mathrm{mL}$ penicillin, $100 \mu \mathrm{g} / \mathrm{mL}$ streptomycin) supplemented with $6 \%$ FCS at a density of 830000 cells/well. After $4 \mathrm{~h}$ initial plating, the latter was replaced with a basal medium supplemented with $100 \mathrm{nM}$ dexamethasone (in order to remove dead cells) and cells were cultured for $24 \mathrm{~h}$.

Human hepatocytes were isolated from pieces of liver resection after surgery for medical purpose. Use of this human material was approved by our local and national ethics committee and legal instances (MESR DC-2008-531). List and information on livers used in this study are shown in supplementary data (Table S1). Process for human hepatocyte isolation has been 
previously described ${ }^{73-74}$ and adapted from the two-step perfusion method described for rat hepatocyte isolation. ${ }^{72}$ Hepatocytes were seeded at $1.10^{6}$ hepatocytes/well on collagen type I 12 wells plate (BectonDickinson, Pont De Claix, France) in platting medium consisting in short term culture medium ${ }^{73-74}$ supplemented with $2 \%$ heat inactivate fetal bovine serum (Lonza, Levallois Perret, France). After overnight attachment, platting medium and unattached cells were eliminated and medium changed to glycogen loading medium.

\section{Pharmacological tests in vitro:}

\section{1) Rat hepatocyte primary culture}

Hepatocytes were loaded in glycogen by incubation $20 \mathrm{~h}$ in loading medium: William's E containing $11.1 \mathrm{mM}$ glucose, $100 \mathrm{U} / \mathrm{mL}$ penicillin, $100 \mu \mathrm{g} / \mathrm{mL}$ streptomycin supplemented with $100 \mathrm{nM}$ dexamethasone, $13.9 \mathrm{mM}$ glucose and $100 \mathrm{nM}$ insulin. After loading period, cells were washed three times with PBS and incubated $3 \mathrm{~h}$ in buffer $^{56}[117.6 \mathrm{mM} \mathrm{NaCl} / 5.4$ $\mathrm{mM} \mathrm{KCl} / 0.82 \mathrm{mM} \mathrm{MgSO}_{4} / 1.5 \mathrm{mM} \mathrm{KH}_{2} \mathrm{PO}_{4} / 20.0 \mathrm{mM}$ Hepes / $9.0 \mathrm{mM} \mathrm{NaHCO}$ / 0.1\% (w/v) BSA / $2.25 \mathrm{mM} \mathrm{CaCl}_{2}(\mathrm{pH}$ 7.4)] without or with GP inhibitor at different concentrations in the presence of $100 \mathrm{nM}$ glucagon (stimulating conditions). After $3 \mathrm{~h}$ incubation, supernatants were collected and frozen at $-20^{\circ} \mathrm{C}$ until glucose quantification.

\section{2) Human hepatocyte primary culture}

Hepatocytes were loaded in glycogen by incubation $20 \mathrm{~h}$ in loading medium: Ham's F12/William's E medium (1:1) supplemented with bovin serum albumin $15 \mu \mathrm{g} / \mathrm{mL}, 66.5 \mu \mathrm{M}$ ethanolamine, $5 \mathrm{mg} / \mathrm{L}$ transferrin, $7.2 \mu \mathrm{M}$ linoleic acid, $100 \mathrm{nM}$ insulin, $0.1 \mu \mathrm{M}$ dexamethasone, $4.5 \mathrm{~g} / \mathrm{L}$ glucose, $0.4 \mathrm{mM}$ sodium pyruvate, $50 \mathrm{mg} / \mathrm{L}$ ascorbic acid, $100 \mathrm{U} / \mathrm{mL}$ penicillin, $100 \mu \mathrm{g} / \mathrm{mL}$ streptomycin (all products from Sigma-Aldrich, St Quentin Fallavier, France). After loading period, cells were washed three times with PBS and incubated $3 \mathrm{~h}$ in DMEM without glucose (Sigma) in the presence of $100 \mathrm{nM}$ glucagon (Novo Nordisk, Puteaux, France) with or without GP inhibitor at different concentrations. After $3 \mathrm{~h}$ incubation, 
supernatants were collected and frozen at $-20^{\circ} \mathrm{C}$ until glucose quantification and plates were washed three times with PBS, dried and frozen at $-20^{\circ} \mathrm{C}$ before intracellular glycogen content measurement.

\section{Glucose and glycogen quantifications}

Glucose release in nmol/well was measured by using a glucose oxidase kit (Megazyme, Wicklow, Ireland). Results were presented in percentage from glucagon stimulation values. Glucose release quantification was performed in 96 wells plate. $10 \mu \mathrm{L}$ of supernatant was incubated with $150 \mu \mathrm{L}$ of glucose oxidase solution, $20 \mathrm{~min}$ at $40^{\circ} \mathrm{C}$. Absorbance at $492 \mathrm{~nm}$ was measured and glucose concentration in sample was calculated using a linear regression from standard curve.

Glycogen content was determined as previously described ${ }^{75}$ with minor modification and measured as glucose released in nmol/well. Glycogen was hydrolyzed to glucose by amyloglucosidase (exo- $\alpha-1.4$-glucosidase) digestion. Amyloglucosidase was diluted at 0.75 $\mathrm{UI} / \mathrm{mL}$ in $0.02 \mathrm{~N}$ sodium acetate buffer $\mathrm{pH} 4.8 .1 \mathrm{~mL} /$ well was added and incubated $2 \mathrm{~h}$ at $40^{\circ} \mathrm{C}$ under agitation. After $2 \mathrm{~h}$, glucose released from glycogen hydrolysis was quantified using the same protocol as described above.

\section{Inhibitory Concentration $50 \%\left(\mathrm{IC}_{50}\right)$ calculation}

Glucose in supernatant and intracellular glycogen content were expressed in percentage of glucagon stimulation values for $\mathrm{IC}_{50}$ calculation. $\mathrm{IC}_{50}$ were determined using GraphPad Prism5 (GraphPad Software, La Jolla, CA, USA). Values are means of three independent experiments. The compounds displaying no effect up to $1 \mathrm{mM}$ in vitro displayed $\mathrm{IC}_{50}$ values above $100 \mu \mathrm{M}$ and were not considered for pharmacological studies in vivo. 


\section{Glucagon challenge in vivo}

Acute test: Experiments were performed in male 10-13 week-old Zucker fa/fa rats (Harlan Laboratories, Gannat, France) housed in groups of 3 on a 12h/12h light-dark schedule cycle. They were allowed free access to both standard food and fresh water. Institutional guidelines for animal care and use were followed.

After 5 days of stabilization, in each experiment, 6 male Zucker fa/fa rats were used. Three rats received a dose of tested compound and three others received the vehicle by oral administration. Twenty minutes later, the glucagon challenge was realized by intra-scapular subcutaneous injection of glucagon $(200 \mu \mathrm{g} / \mathrm{kg})$. Blood samples were collected from the tail vein before and after glucagon administration at $0,10,20,45 \mathrm{~min}$. After centrifugation at $4^{\circ} \mathrm{C}$, plasma glucose samples were measured immediately by the glucose oxidase method. ${ }^{76}$

Finally, either vehicle (4-5 mL/kg, per os) or GP inhibitors $(7.5-90 \mathrm{mg} / \mathrm{kg}$, per os) were orally administrated 65 minutes prior to the final blood glucose measurement to assess their ability to reduce the glucagon induced hyperglycaemia. ${ }^{77}$

Subchronic tests: After 5 days of stabilization, 6 male Zucker fa/fa rats were treated; three of them received a dose of GP inhibitor and three others received the vehicle by oral administration during 4 days. After the fourth administration, animals were submitted to a glucagon challenge test as previously described. Animals were then treated 2 additional days. They were then submitted to an oral glucose tolerance test (OGTT, glucose at $3 \mathrm{~g} / \mathrm{kg}$ ). Before the OGTT, animals were deprived of food overnight. Blood samples were collected from the tail vein before and after glucose administration at different times. After centrifugation at $4{ }^{\circ} \mathrm{C}$, plasma glucose levels were measured by the glucose oxidase method ${ }^{76}$ and plasma insulin concentrations using a radio-immunological method. ${ }^{78}$ 


\section{Data analysis}

All data were expressed as means \pm SEM. Multiple group comparisons were performed by analysis of variance (ANOVA) followed by Fisher's protected Least Significant Difference test at $* \mathrm{p}<0.05, * * \mathrm{p}<0.01$ or $* * * \mathrm{p}<0.001$ using the Stat Graphics software.

For in vivo experiments, glycaemia and insulinemia time curves were expressed in $\mathrm{mmol} / \mathrm{L}$ and $\mathrm{ng} / \mathrm{mL}$ respectively. Plasma glucose and insulin concentrations were expressed as variations (delta), meaning that the basal value of glycaemia or insulinemia was subtracted for each individual value and for each rat. The areas under the curve (AUC) for 60 min were established.

\section{References}

(1) New Therapeutic Strategies for Type 2 Diabetes: Small Molecule Approaches. Jones, Rob M. ed.; RSC Drug Discovery, Dorset Press: Dorchester, UK, 2012.

(2) Ross, S. A.; Gulve, E. A.; Wang, M., Chemistry and Biochemistry of Type 2 Diabetes. Chem. Rev. 2004, 104, 1255-1282.

(3) Henke, B. R., Inhibition of glycogen phosphorylase as a strategy for the treatment of type 2 diabetes mellitus. In New Therapeutic Strategies for Type 2 Diabetes: Small Molecule Approaches, Jones, R. M., Ed. RSC Drug Discovery, Dorset Press: Dorchester, UK, 2012; pp 324-365.

(4) Cori, C. F.; Cori, G. T., Mechanism of formation of hexosemonophosphate in muscle and isolation of a new phosphate monoester. Proc. Soc. Exp. Biol. Med. 1936, 34, 702705.

(5) Johnson, L. N., The regulation of protein phosphorylation. Biochem. Soc. Trans. 2009, 37, 627-641.

(6) Johnson, L. N., Glycogen phosphorylase: control by phosphorylation and allosteric effectors. FASEB J. 1992, 6, 2274-2282.

(7) Wen, X.; Sun, H.; Liu, J.; Cheng, K.; Zhang, P.; Zhang, L.; Hao, J.; Zhang, L.; Ni, P.; Zographos, S. E.; Leonidas, D. D.; Alexacou, K.-M.; Gimisis, T.; Hayes, J. M.; Oikonomakos, N. G., Naturally Occurring Pentacyclic Triterpenes as Inhibitors of Glycogen Phosphorylase: Synthesis, Structure-Activity Relationships, and X-ray Crystallographic Studies J. Med. Chem. 2008, 51, 3540-3554.

(8) Loughlin, W. A.; Pierens, G. K.; Petersson, M. J.; Henderson, L. C.; Healy, P. C., Evaluation of novel Hyphodermin derivatives as Glycogen Phosphorylase a inhibitors. Bioorg. Med. Chem. 2008, 16, 6172-6178.

(9) Praly, J.-P.; Vidal, S., Inhibition of Glycogen Phosphorylase in the Context of Type 2 Diabetes, with Focus on Recent Inhibitors Bound at the Active Site. Mini-Rev. Med. Chem. 2010, 10, 1102-1126. 
(10) Somsák, L.; Nagy, V.; Hadady, Z.; Docsa, T.; Gergely, P., Glucose analog inhibitors of glycogen phosphorylases as potential antidiabetic agents. Recent developments. Curr. Pharm. Des. 2003, 9, 1177-1189.

(11) Somsák, L.; Nagy, V.; Hadady, Z.; Felföldi, N.; Docsa, T.; Gergely, P., Recent developments in the synthesis and evaluation of glucose analog inhibitors of glycogen phosphorylases as potential antidiabetic agents. Frontiers Med. Chem. 2005, 2, 253-272.

(12) Khan, M., Sugar-derived Heterocycles and Their Precursors as Inhibitors Against Glycogen Phosphorylases (GP). Top. Heterocycl. Chem. 2007, 9, 33-52.

(13) Gimisis, T., Synthesis of N-glucopyranosidic derivatives as potential inhibitors that bind at the catalytic site of Glycogen Phosphorylase. Mini-Rev. Med. Chem. 2010, 10, 11271138.

(14) Somsák, L., Glucose derived inhibitors of glycogen phosphorylase. C. R. Chimie 2011, $14,211-223$.

(15) Oikonomakos, N. G., Glycogen Phosphorylase as a molecular target for type 2 diabetes therapy. Curr. Prot. Pept. Sci. 2002, 3, 561-586.

(16) Somsák, L.; Czifrák, K.; Tóth, M.; Bokor, E.; Chrysina, E. D.; Alexacou, K. M.; Hayes, J. M.; Tiraidis, C.; Lazoura, E.; Leonidas, D. D.; Zographos, S. E.; Oikonomakos, N. G., New inhibitors of glycogen phosphorylase as potential antidiabetic agents. Curr. Med. Chem. 2008, 15, 2933-2983.

(17) Oikonomakos, N. G.; Somsák, L., Advances in glycogen phosphorylase inhibitor design. Curr. Opin. Invest. Drugs 2008, 9, 379-395.

(18) Henke, B. R.; Sparks, S. M., Glycogen phosphorylase inhibitors. Mini-Rev. Med. Chem. 2006, 6, 845-857.

(19) Chrysina, E. D., The prototype of Glycogen Phosphorylase. Mini-Rev. Med. Chem. 2010, 10, 1093-1101.

(20) Hayes, J.; Kantsadi, A.; Leonidas, D., Natural products and their derivatives as inhibitors of glycogen phosphorylase: potential treatment for type 2 diabetes. Phytochem. Rev. 2014, 13, 471-498.

(21) Krimm, I.; Lancelin, J.-M.; Praly, J.-P., Binding Evaluation of Fragment-Based Scaffolds for Probing Allosteric Enzymes. J. Med. Chem.2012, 55, 1287-1295.

(22) Ercan-Fang, N.; Taylor, M. R.; Treadway, J. L.; Levy, C. B.; Genereux, P. E.; Gibbs, E. M.; Rath, V. L.; Kwon, Y.; Gannon, M. C.; Nuttall, F. Q., Endogenous effectors of human liver glycogen phosphorylase modulate effects of indole-site inhibitors. Am. J. Physiol. Endocrinol. Metab. 2005, 289, E366-E372.

(23) Yu, L. J.; Chen, Y.; Treadway, J. L.; McPherson, R. K.; McCoid, S. C.; Gibbs, E. M.; Hoover, D. J., Establishment of Correlation between in Vitro Enzyme Binding Potency and in Vivo Pharmacological Activity: Application to Liver Glycogen Phosphorylase a Inhibitors. J. Pharmacol. Exp. Ther. 2006, 317, 1230-1237.

(24) Zhang, L.; Li, H.; Zhu, Q.; Liu, J.; Chen, L.; Leng, Y.; Jiang, H.; Liu, H., Benzamide derivatives as dual-action hypoglycemic agents that inhibit glycogen phosphorylase and activate glucokinase. Bioorg. Med. Chem. 2009, 17, 7301-7312.

(25) Agius, L., Physiological control of liver glycogen metabolism: lessons from novel glycogen phosphorylase inhibitors. Mini-Rev. Med. Chem. 2010, 10, 1175-1187.

(26) Agius, L., New hepatic targets for glycaemic control in diabetes. Best Pract. Res. Clin. Endocrinol. Metab. 2007, 21, 587-605.

(27) Docsa, T.; Czifrák, K.; Hüse, C.; Somsák, L.; Gergely, P., Effect of glucopyranosylidene-spiro-thiohydantoin on glycogen metabolism in liver tissues of streptozotocin-induced and obese diabetic rats. Mol. Med. Rep. 2011, 3, 477-481. 
(28) Baker, D. J.; Greenhaff, P. L.; Timmons, J. A., Glycogen phosphorylase inhibition as a therapeutic target: a review of the recent patent literature. Exp. Opin. Ther. Pat. 2006, $16,459-466$.

(29) Vizan, P.; Sanchez-Tena, S.; Alcarraz-Vizan, G.; Soler, M.; Messeguer, R.; Pujol, M. D.; Lee, W.-N. P.; Cascante, M., Characterization of the metabolic changes underlying growth factor angiogenic activation: identification of new potential therapeutic targets. Carcinogenesis 2009, 30, 946-952.

(30) Xu, L.; Sun, H., Mini-Rev. Med. Chem. 2010, 10, 1188-1193.

(31) Somsák, L.; Nagy, V.; Docsa, T.; Tóth, M.; Gergely, P., Gram-scale synthesis of a glucopyranosylidene-spiro-thiohydantoin and its effect on hepatic glycogen metabolism studied in vitro and in vivo. Tetrahedron: Asymmetry 2000, 11, 405-408.

(32) Nagy, L.; Docsa, T.; Szántó, M.; Brunyánszki, A.; Hegedűs, C.; Márton, J.; Kónya, B.; Virág, L.; Somsák, L.; Gergely, P.; Bai, P., Glycogen Phosphorylase Inhibitor N-(3,5Dimethyl-Benzoyl)-N'-( $\beta$-D-Glucopyranosyl)Urea Improves Glucose Tolerance under Normoglycemic and Diabetic Conditions and Rearranges Hepatic Metabolism. PLoS ONE 2013, 8, e69420.

(33) Benltifa, M.; Hayes, J. M.; Vidal, S.; Gueyrard, D.; Goekjian, P. G.; Praly, J.-P.; Kizilis, G.; Tiraidis, C.; Alexacou, K.-M.; Chrysina, E. D.; Zographos, S. E.; Leonidas, D. D.; Archontis, G.; Oikonomakos, N. G., Glucose-based spiro-isoxazolines: A new family of potent glycogen phosphorylase inhibitors. Bioorg. Med. Chem. 2009, 17, 7368-7380.

(34) Benltifa, M.; Vidal, S.; Gueyrard, D.; Goekjian, P. G.; Msaddek, M.; Praly, J.-P., 1,3Dipolar cycloaddition reactions on carbohydrate-based templates: synthesis of spiroisoxazolines and 1,2,4-oxadiazoles as glycogen phosphorylase inhibitors. Tetrahedron Lett. 2006, 47, 6143-6147.

(35) Bichard, C. J. F.; Mitchell, E. P.; Wormald, M. R.; Watson, K. A.; Johnson, L. N.; Zographos, S. E.; Koutra, D. D.; Oikonomakos, N. G.; Fleet, G. W. J., Potent inhibition of glycogen phosphorylase by a spirohydantoin of glucopyranose: First pyranose analogues of hydantocidin. Tetrahedron Lett. 1995, 36, 2145-2148.

(36) Ösz, E.; Somsák, L.; Szilágyi, L.; Kovács, L.; Docsa, T.; Tóth, B.; Gergely, P., Efficient inhibition of muscle and liver glycogen phosphorylases by a new glucopyranosylidenespiro-thiohydantoin. Bioorg. Med. Chem. Lett. 1999, 9, 1385-1390.

(37) Krülle, T. M.; Watson, K. A.; Gregoriou, M.; Johnson, L. N.; Crook, S.; Watkin, D. J.; Griffiths, R. C.; Nash, R. J.; Tsitsanou, K. E.; Zographos, S. E.; Oikonomakos, N. G.; Fleet, G. W. J., Specific inhibition of glycogen phosphorylase by a spirodiketopiperazine at the anomeric position of glucopyranose. Tetrahedron Lett. 1995, 36, 8291-8294.

(38) Praly, J.-P.; Faure, R.; Joseph, B.; Kiss, L.; Rollin, P., Synthesis, structure and enzymatic evaluation of new spiro oxathiazole sugar derivatives. Tetrahedron 1994, 50, 6559-6568.

(39) Nagy, V.; Benltifa, M.; Vidal, S.; Berzsényi, E.; Teilhet, C.; Czifrák, K.; Batta, G.; Docsa, T.; Gergely, P.; Somsák, L.; Praly, J.-P., Glucose-based spiro-heterocycles as potent inhibitors of glycogen phosphorylase. Bioorg. Med. Chem. 2009, 17, 5696-5707.

(40) Somsák, L.; Nagy, V.; Vidal, S.; Czifrák, K.; Berzsényi, E.; Praly, J.-P., Novel design principle validated: Glucopyranosylidene-spiro-oxathiazole as new nanomolar inhibitor of glycogen phosphorylase, potential antidiabetic agent. Bioorg. Med. Chem. Lett. 2008, $18,5680-5683$.

(41) Czifrák, K.; Páhi, A. s.; Deák, S.; Kiss-Szikszai, A.; Kövér, K. E.; Docsa, T.; Gergely, P. 1.; Alexacou, K.-M.; Papakonstantinou, M.; Leonidas, D. D.; Zographos, S. E.; Chrysina, E. D.; Somsák, L., Glucopyranosylidene-spiro-iminothiazolidinone, a new bicyclic ring system: Synthesis, derivatization, and evaluation for inhibition of glycogen 
phosphorylase by enzyme kinetic and crystallographic methods. Bioorg. Med. Chem. 2014, 22, 4028-4041.

(42) Páhi, A.; Czifrák, K.; Kövér, K. E.; Somsák, L., Anomeric spirocycles by solvent incorporation: reactions of O-peracylated (glyculopyranose and glyculopyranosyl bromide)onamide derivatives with ketones. Carbohydr. Res. 2015, 11, 192-201.

(43) Tóth, M.; Somsák, L., exo-Glycals from glycosyl cyanides. First generation of Cglycosylmethylene carbenes from 2,5- and 2,6-anhydroaldose tosylhydrazones. J. Chem. Soc. Perkin. Trans. 1 2001, 942-943.

(44) Tóth, M.; Köver, K. E.; Bényei, A.; Somsák, L., C-Glycosylmethylene carbenes: synthesis of anhydro-aldose tosylhydrazones as precursors; generation and a new synthetic route to exo-glycals. Org. Biomol. Chem. 2003, 1, 4039-4046.

(45) Verga, D.; Nadai, M.; Doria, F.; Percivalle, C.; Di Antonio, M.; Palumbo, M.; Richter, S. N.; Freccero, M., Photogeneration and Reactivity of Naphthoquinone Methides as Purine Selective DNA Alkylating Agents. J. Am. Chem. Soc. 2010, 132, 14625-14637.

(46) Shing, T. K. M.; Wong, W. F.; Cheng, H. M.; Kwok, W. S.; So, K. H., Intramolecular Nitrile Oxide-Alkene Cycloaddition of Sugar Derivatives with Unmasked Hydroxyl Group(s). Org. Lett. 2007, 9, 753-756.

(47) Jen, T.; Mendelsohn, B. A.; Ciufolini, M. A., Oxidation of $\alpha$-Oxo-Oximes to Nitrile Oxides with Hypervalent Iodine Reagents. J. Org. Chem. 2011, 76, 728-731.

(48) Yun, H.; Paek, S.-M.; Jung, J.-W.; Kim, N.-J.; Kim, S.-H.; Suh, Y.-G., First total syntheses of (-)-macrosphelides $\mathrm{J}$ and $\mathrm{K}$ and elucidation of their absolute configuration. Chem. Commun. 2009, 2463-2465.

(49) Beleníkii, L. I., Nitrile Oxides in Nitrile Oxides, Nitrones, And Nitronates In Organic Synthesis : Novel Strategies in Synthesis, $2^{\text {nd }}$ ed.; Feuer, H., Ed. John Wiley \& Sons, Inc. : 2008; pp 1-127.

(50) Roy, B.; De, R., Enhanced rate of intramolecular nitrile oxide cycloaddition and rapid synthesis of isoxazoles and isoxazolines. Monatsh. Chem. 2010, 141, 763-771.

(51) Sammelson, R. E.; Miller, R. B.; Kurth, M. J., Linear Tetraheterocycles Composed of Both Bidentate Diisoxazole and Bidentate Isoxazole-Furyl/Thienyl/Pyridyl Motifs. J. Org. Chem. 2000, 65, 2225-2228.

(52) Taillefumier, C.; Chapleur, Y., Synthesis and uses of exo-glycals. Chem. Rev. 2004, 104, 263-292.

(53) Zhang, P.-Z.; Li, X.-L.; Chen, H.; Li, Y.-N.; Wang, R., The synthesis and biological activity of novel spiro-isoxazoline $\mathrm{C}$-disaccharides based on 1,3-dipolar cycloaddition of exo-glycals and sugar nitrile oxides. Tetrahedron Lett. 2007, 48, 7813-7816.

(54) Tóth, M.; Kun, S.; Bokor, É.; Benltifa, M.; Tallec, G.; Vidal, S.; Docsa, T.; Gergely, P.; Somsák, L.; Praly, J.-P., Synthesis and structure-activity relationships of C-glycosylated oxadiazoles as inhibitors of glycogen phosphorylase. Bioorg. Med. Chem. 2009, 17, 4773-4785.

(55) Fosgerau, K.; Westergaard, N.; Quistorff, B.; Grunnet, N.; Kristiansen, M.; Lundgren, K., Kinetic and Functional Characterization of 1,4-Dideoxy-1,4-imino-d-arabinitol: A Potent Inhibitor of Glycogen Phosphorylase with Anti-hyperglyceamic Effect in ob/ob Mice. Arch. Biochem. Biophys. 2000, 380, 274-284.

(56) Andersen, B.; Rassov, A.; Westergaard, N.; Lundgren, K., Inhibition of glycogenolysis in primary rat hepatocytes by 1, 4-dideoxy-1,4-imino-D-arabinitol. Biochem. J. 1999, 342, 545-550.

(57) Fosgerau, K.; Breinholt, J.; McCormack, J. G.; Westergaard, N., Evidence against Glycogen Cycling of Gluconeogenic Substrates in Various Liver Preparations. J. Biol. Chem. 2002, 277, 28648-28655. 
(58) Mackay, P.; Ynddal, L.; Andersen, J. V.; McCormack, J. G., Pharmacokinetics and antihyperglycaemic efficacy of a novel inhibitor of glycogen phosphorylase, 1,4-dideoxy1,4-imino-d- arabinitol, in glucagon-challenged rats and dogs and in diabetic ob/ob mice. Diab. Obes. Metab. 2003, 5, 397-407.

(59) Gloster, T. M.; Zandberg, W. F.; Heinonen, J. E.; Shen, D. L.; Deng, L.; Vocadlo, D. J., Hijacking a biosynthetic pathway yields a glycosyltransferase inhibitor within cells. Nat. Chem. Biol. 2011, 7, 174-181.

(60) Cecioni, S.; Vocadlo, D. J., Tools for probing and perturbing O-GlcNAc in cells and in vivo. Curr. Opin. Chem. Biol. 2013, 17, 719-728.

(61) Carroux, C. J.; Rankin, G. M.; Moeker, J.; Bornaghi, L. F.; Katneni, K.; Morizzi, J.; Charman, S. A.; Vullo, D.; Supuran, C. T.; Poulsen, S.-A., A Prodrug Approach Toward Cancer-Related Carbonic Anhydrase Inhibition. J. Med. Chem. 2013, 56, 9623-9634.

(62) Sampathkumar, S. G.; Campbell, C. T.; Weier, C.; Yarema, K. J., Drugs Future 2006, 31, 1-18.

(63) Freeman, S.; Bartlett, J. B.; Convey, G.; Hardern, I.; Teague, J. L.; Loxham, S. J. G.; Allen, J. M.; Poucher, S. M.; Charles, A. D., Sensitivity of glycogen phosphorylase isoforms to indole site inhibitors is markedly dependent on the activation state of the enzyme. Br. J. Pharmacol. 2006, 149, 775-785.

(64) Martin, W. H.; Hoover, D. J.; Armento, S. J.; Stock, I. A.; McPherson, R. K.; Danley, D. E.; Stevenson, R. W.; Barrett, E. J.; Treadway, J. L., Discovery of a human liver glycogen phosphorylase inhibitor that lowers blood glucose in vivo. Proc. Natl. Acad. Sci. U.S.A. 1998, 95, 1776-1781.

(65) Roden, M.; Bernroider, E., Hepatic glucose metabolism in humans - its role in health and disease. Best Pract. Res. Clin. Endocrinol. Metab. 2003, 17, 365-383.

(66) Combettes, M.; Kargar, C., Newly Approved and Promising Antidiabetic Agents. Thérapie 2007, 62, 293-310.

(67) Docsa, T.; Marics, B.; Nemeth, J.; Huse, C.; Somsak, L.; Gergely, P.; Peitl, B., Insulin Sensitivity is Modified by a Glycogen Phosphorylase Inhibitor: GlucopyranosylideneSpiro-Thiohydantoin in Streptozotocin-Induced Diabetic Rats Top. Curr. Med. Chem. 2015, 15, 2390-2394.

(68) Pedras, M. S. C.; Suchy, M.; Ahiahonu, P. W. K., Unprecedented chemical structure and biomimetic synthesis of erucalexin, a phytoalexin from the wild crucifer Erucastrum gallicum. Org. Biomol. Chem. 2006, 4, 691-701.

(69) Saheki, S.; Takeda, A.; Shimazu, T., Assay of inorganic phosphate in the mild pH range, suitable for measurement of glycogen phosphorylase activity. Anal. Biochem. 1985, 148, 277-281.

(70) Fiske, C. H.; Subbarow, Y., The colorimetric determination of phosphorus. J. Biol. Chem. 1925, 66, 375-400.

(71) Fischer, E. H.; Krebs, E. G., [49a] Muscle phosphorylase b: x Glucose-1-phosphate+ $\mathrm{G}_{\mathrm{n}}$ $\rightleftarrows \mathrm{G}_{\mathrm{n}+\mathrm{x}}+\mathrm{x}$ inorganic phosphate (where $\mathrm{G}_{\mathrm{n}}$ designates glycogen containing $\mathrm{n}$ glucose residues). Meth. Enzymol. 1962, 5, 369-373.

(72) Seglen, P. O., Preparation of Isolated Rat Liver Cells. Meth. Cell Biol. 1976, 13, 29-83.

(73) Pichard, L.; Raulet, E.; Fabre, G.; Ferrini, J.; Ourlin, J.-C.; Maurel, P., Human Hepatocyte Culture. Meth. Mol. Biol. 2006, 320, 283-293.

(74) Duret, C.; Vinci, B.; Sbrana, T.; Klieber, S.; Maurel, P.; Daujat-Chavanieu, M.; Ahluwalia, A., Cultivation of human hepatocytes in the quasi-vivo system: from isolation and seeding to quantification of XME (Xenobiotic Metabolizing Enzymes) expression and activity. In Cellular In Vitro Testing: Methods and Protocols Haycock, J.; Ahluwalia, A.; Wilkinson, J. M., Eds. Pan Stanford Publishing: 2014; Chap. 3, pp. $35-52$. 
(75) Gomez-Lechon, M. J.; Ponsoda, X.; Castell, J. V., A Microassay for Measuring Glycogen in 96-Well-Cultured Cells. Anal. Biochem. 1996, 236, 296-301.

(76) Trinder, P., Determination of blood glucose using an oxidase-peroxidase system with a non-carcinogenic chromogen. J. Clin. Pathol. 1969, 22, 158-161.

(77) Loxham, S. J. G.; Teague, J.; Poucher, S. M.; De Schoolmeester, J.; Turnbull, A. V.; Carey, F., Glucagon challenge in the rat: A robust method for the in vivo assessment of Glycogen phosphorlyase inhibitor efficacy. J. Pharmacol. Toxicol. Meth. 2007, 55, 7177.

(78) Herbert, V.; Lau, K.; Gottlieb, C.; Bleicher, S., Coated Charcoal Immunoassay of Insulin. J. Clin. Endocrinol. Metab. 1965, 25, 1375-1384. 

Supplementary Material - For Publication Online
Click here to download Supplementary Material - For Publication Online: Supplnfo_Vidal.doc

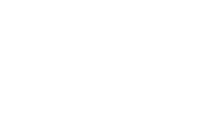

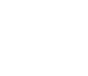

.


$\left(\frac{100}{20}\right.$

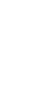
更 更 更 更 更 更 更 更 更 更 更 更 更 更 